ARTICLE

https://doi.org/10.1038/s41467-020-17781-6

\title{
The natural function of the malaria parasite's chloroquine resistance transporter
}

Sarah H. Shafik , Simon A. Cobbold (10 ${ }^{2}$, Kawthar Barkat ${ }^{1}$, Sashika N. Richards ${ }^{1}$, Nicole S. Lancaster ${ }^{1}$, Manuel Llinás (iD ${ }^{3}$, Simon J. Hogg (10 ${ }^{1}$, Robert L. Summers ${ }^{1}$, Malcolm J. McConville (i] ${ }^{2}$ \& Rowena E. Martin (i) ${ }^{1 \times}$

The Plasmodium falciparum chloroquine resistance transporter (PfCRT) is a key contributor to multidrug resistance and is also essential for the survival of the malaria parasite, yet its natural function remains unresolved. We identify host-derived peptides of 4-11 residues, varying in both charge and composition, as the substrates of PfCRT in vitro and in situ, and show that PfCRT does not mediate the non-specific transport of other metabolites and/or ions. We find that drug-resistance-conferring mutations reduce both the peptide transport capacity and substrate range of PfCRT, explaining the impaired fitness of drug-resistant parasites. Our results indicate that PfCRT transports peptides from the lumen of the parasite's digestive vacuole to the cytosol, thereby providing a source of amino acids for parasite metabolism and preventing osmotic stress of this organelle. The resolution of PfCRT's native substrates will aid the development of drugs that target PfCRT and/or restore the efficacy of existing antimalarials.

\footnotetext{
${ }^{1}$ Research School of Biology, The Australian National University, Canberra, ACT 2601, Australia. ${ }^{2}$ Bio21 Molecular Science and Biotechnology Institute, University of Melbourne, Melbourne, VIC 3052, Australia. ${ }^{3}$ Department of Biochemistry and Molecular Biology, Department of Chemistry, and Huck Center for Malaria Research, The Pennsylvania State University, University Park, PA 16802, USA. ${ }^{凶}$ email: rowena.martin@anu.edu.au
} 


\section{T} o grow and multiply within the erythrocyte, the malaria parasite takes up the host cell cytosol into an acidic compartment known as the digestive vacuole (DV, $\mathrm{pH}$ $5.0-5.5^{1,2}$ ). The internalised host proteins, $50-80 \%$ of which are haemoglobin ${ }^{3,4}$, are degraded by DV-localised proteases into peptides and amino acids 5 . The digestion of the erythrocyte cytosol provides space ${ }^{6}$ and amino acids ${ }^{7}$ for parasite growth and multiplication, and helps maintain the osmotic balance of the parasitised cell ${ }^{8,9}$. Consistent with its crucial role in the biology of the parasite, the DV is also where many antimalarials act, accumulate and/or are activated ${ }^{10}$.

The P. falciparum 'chloroquine resistance transporter' (PfCRT) resides in the DV membrane and is pivotal to the normal physiology of this organelle as well as to its extensive involvement in drug resistance ${ }^{11-13}$. PfCRT was originally identified as the main determinant of chloroquine (CQ) resistance, but mutations in this protein are now known to modulate the parasite's sensitivity to many current and upcoming antimalarials ${ }^{14}$. The main mechanism by which these mutations confer drug resistance is through enabling the transporter to efflux a drug, such as CQ, from the DV and thus away from its primary site of action ${ }^{10,15,16}$.

PfCRT is also essential for the survival of the parasite and has itself been identified as a drug target ${ }^{17-19}$. For instance, potent inhibition of mutant PfCRT results in parasite death 20,21 and downregulation of PfCRT expression causes impaired growth and DV swelling 22 . Furthermore, the mutations that confer drug resistance typically impose a fitness cost upon the parasite, the severity of which is dependent upon the number and nature of the mutations ${ }^{23-27}$. For example, the ' $\mathrm{Dd} 2$ ' isoform ( $\mathrm{PfCRT} \mathrm{Dd}^{\mathrm{D} 2}$ ) imparts a significant fitness cost (and a high level of CQ resistance), whereas the 'Ecul110' isoform (PfCRTEcul110) imposes a smaller fitness disadvantage but also confers a lower level of CQ resistance. Moreover, two PfCRT mutations that arose separately under in vitro drug pressure (C101F and L272F) incur both a fitness cost and a monstrously swollen DV ${ }^{13}$.

Although these findings indicate that PfCRT is crucial for parasite growth and replication, and for maintaining the osmotic homoeostasis of the DV, its native substrates and function remain unresolved. Attempts to characterise PfCRT in heterologous expression systems have produced wildly disparate results, with it being claimed to function as either a $\mathrm{Cl}^{-}$channel ${ }^{28,29}$, a $\mathrm{H}^{+}$ pump $^{30}$, a non-specific cation channel ${ }^{31}$, an activator of $\mathrm{H}^{+}$ pumps and of non-specific cation channels ${ }^{31}$, a glutathione transporter $^{32}$, a non-specific transporter of inorganic and organic cations as well as of many other metabolites ${ }^{33}$, or an $\mathrm{Fe}^{2+} / \mathrm{Fe}^{3+}$ transporter ${ }^{34}$. Moreover, none of these studies undertook experiments with parasites to substantiate that PfCRT exhibited the proposed transport activity in situ and that mediating this activity was the protein's physiological role.

Here, we use the Xenopus oocyte expression system in conjunction with measurements of solute transport, drug activity and metabolite levels in transgenic parasite lines to provide a detailed elucidation of the native substrate-specificity and physiological role of PfCRT. We show that PfCRT functions to export hostderived peptides 4-11 residues in length from the parasite's DV, and that the protein does not behave as a non-specific transporter of other metabolites and/or ions. The transport of peptides and peptide mimics via PfCRT is saturable, blocked by known PfCRT inhibitors, and is dependent on protons as well as on a cosubstrate that remains to be identified. Relative to the wild-type protein, the drug-resistance-conferring isoforms of PfCRT recognise far fewer peptides and peptide mimics, and have markedly lower maximum rates of peptide transport. The reduced capacities of mutant PfCRT isoforms for transporting peptides out of the DV results in the accumulation of the substrate peptides in drug-resistant parasite lines. Together, our findings provide a molecular basis for why PfCRT is essential for parasite survival and why drug-resistance-conferring mutations in the transporter impart a fitness cost. We present a mechanistic model in which the PfCRT-mediated transport of peptides from the DV to the cytosol serves to (1) provide a source of amino acids to support the parasite's high growth rate and (2) reduce peptide levels within the DV and thereby prevent the osmotic stress, swelling and dysfunction of this organelle.

\section{Results}

Cis-inhibition screens identify putative substrates of PfCRT. A large collection of metabolites and ions was screened for molecules that interact with the substrate-binding cavity of PfCRT in the Xenopus oocyte system ${ }^{15}$. Our approach utilised two CQresistance-conferring isoforms of PfCRT (PfCRT Ecul110 and PfCRT ${ }^{\text {Dd2 }}$ ) which, unlike wild-type PfCRT (PfCRT ${ }^{3 D 7}$ ), transport tritiated CQ $\left.\left({ }^{3} \mathrm{H}\right] \mathrm{CQ}\right)$ into the oocyte ${ }^{16}$. This property was exploited to detect unlabelled solutes that inhibit $\left[{ }^{3} \mathrm{H}\right] \mathrm{CQ}$ uptake, consistent with them interacting with the mutant transporter's substrate-binding cavity (Fig. 1a).

None of the test solutes affected the accumulation of $\left[{ }^{3} \mathrm{H}\right] \mathrm{CQ}$ in the negative controls, and most solutes also failed to cis-inhibit $\left[{ }^{3} \mathrm{H}\right] \mathrm{CQ}$ transport via PfCRT ${ }^{\mathrm{Ecul11}} 10$ or PfCRTDd2 (Fig. 1b-d; Supplementary Data 1, 2 and Supplementary Note 1). By contrast, almost all of the 95 peptides screened strongly cisinhibited $\left[{ }^{3} \mathrm{H}\right] \mathrm{CQ}$ transport by both PfCRTEcul110 and PfCRTDd2. The test peptides were $2-25$ residues in length and most occur in haemoglobin or other erythrocyte proteins. Only the dipeptides LH and GQ were without effect. Two haemoglobin-derived peptides, VDPVNF (VF-6) and HVDDM (HM-5), were selected for further characterisation and were confirmed to cis-inhibit $\left[{ }^{3} \mathrm{H}\right] \mathrm{CQ}$ transport via $\mathrm{PfCRT}^{\mathrm{Dd} 2}$ in a concentration-dependent manner (Fig. 1e).

Peptides containing 4-11 residues trans-stimulate PfCRT. The cis-inhibition assay identifies compounds that interact with PfCRT, but does not distinguish between solutes that inhibit (and are not translocated) and those that are substrates of PfCRT. We therefore employed a trans-stimulation assay to investigate whether the host-derived peptides are substrates of PfCRT (Fig. 2a). Trans-stimulation is a phenomenon exhibited by many carrier-type transporters (such as PfCRT ${ }^{21,35}$ ) whereby the reorientation of the binding site between the two faces of the membrane occurs more rapidly when it is occupied by a substrate than when it is empty (Supplementary Note 2). This property means that the PfCRT-mediated uptake of $\left[{ }^{3} \mathrm{H}\right] \mathrm{CQ}$ from the extracellular solution will increase when an unlabelled substrate is present on the cytosolic face of the membrane, but will be unaffected by the presence of solutes that do not interact with the transporter ${ }^{21}$.

None of the test solutes affected $\left[{ }^{3} \mathrm{H}\right] \mathrm{CQ}$ accumulation in the negative controls, and LH was without effect in all oocyte types (Fig. 2b-g; Supplementary Fig. 1 and Supplementary Data 1,2). Moreover, the solutes that had failed to cis-inhibit PfCRT also did not trans-stimulate $\left[{ }^{3} \mathrm{H}\right] \mathrm{CQ}$ uptake, confirming that they are not substrates of the transporter (Fig. 2b, c, g; Supplementary Note 2, 3). By contrast, of the 93 peptides found to cis-inhibit PfCRT, 32 transstimulated $\left[{ }^{3} \mathrm{H}\right] \mathrm{CQ}$ transport via PfCRTEcul110 and 23 of these peptides also trans-stimulated PfCRT ${ }^{\mathrm{Dd} 2}$. Somewhat unexpectedly, 39 peptides trans-stimulated $\left[{ }^{3} \mathrm{H}\right] \mathrm{CQ}$ transport via PfCRT ${ }^{3 \mathrm{D} 7}$. This finding revealed that although CQ transport via PfCRT ${ }^{3 \mathrm{D} 7}$ cannot be detected under normal conditions in the oocyte system or in situ ${ }^{36,37}$, the wild-type transporter can mediate a low level of CQ transport when trans-stimulated by high concentrations of a peptide substrate. The trans-stimulation of PfCRT $^{3 \mathrm{D} 7}$ by VF- 6 
a

cis-inhibition of $\left[{ }^{3} \mathrm{H}\right] \mathrm{CQ}$ transport by an unlabelled test solute

Legend:

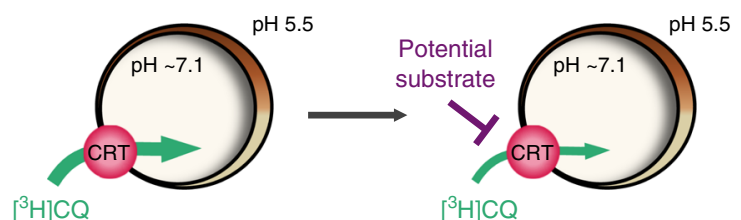

$\square$ Non-expressing oocytes

PfCRT $^{3 \mathrm{D} 7}$

PfCRT $^{\text {Ecu1110 }}$

PfCRT ${ }^{\text {Dd2 }}$
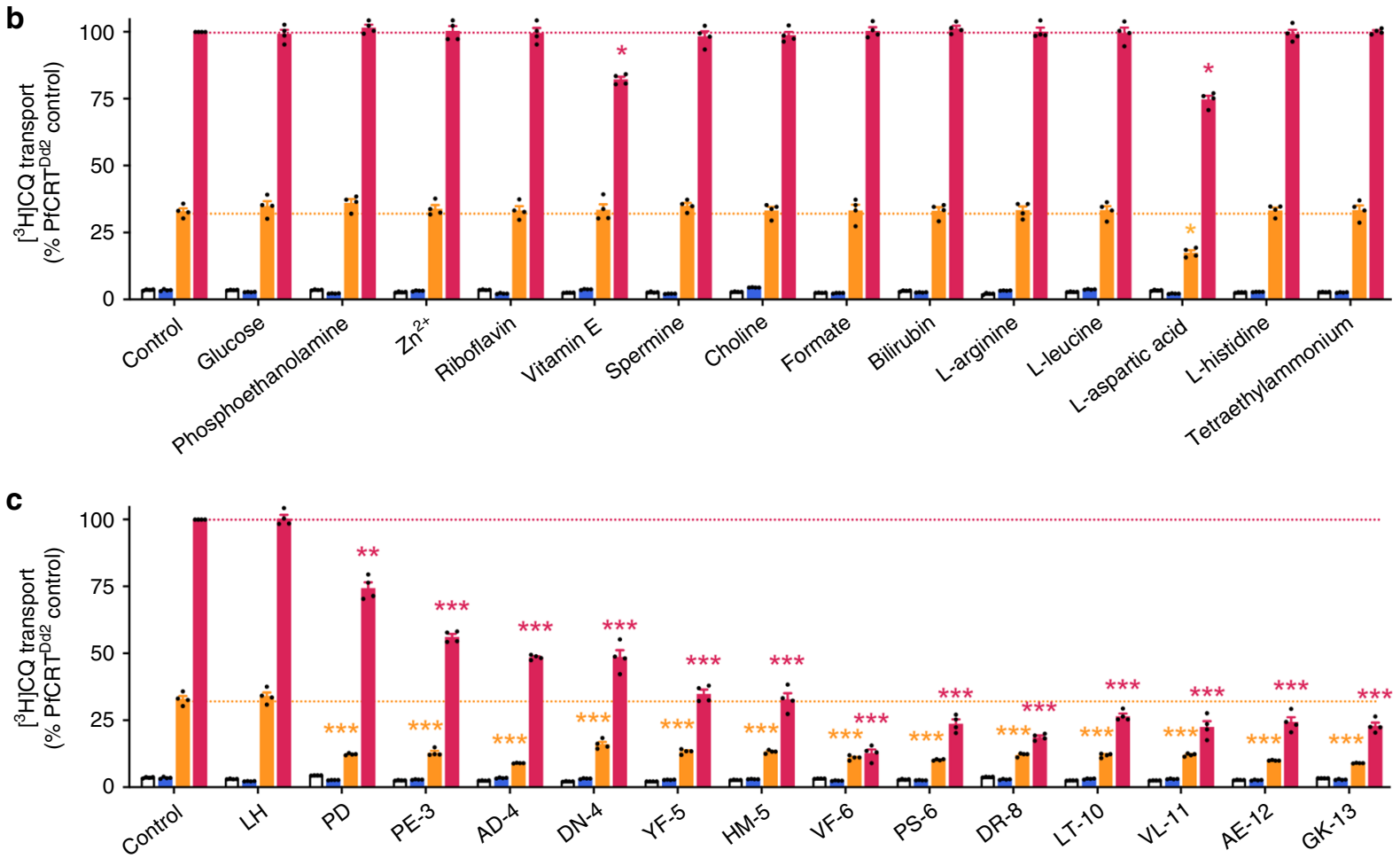

d

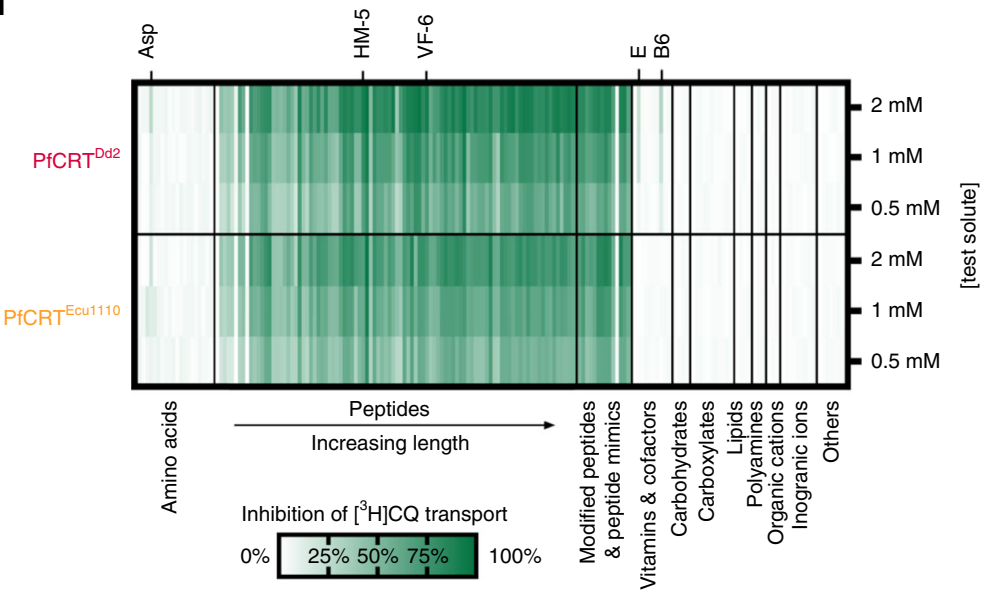

e
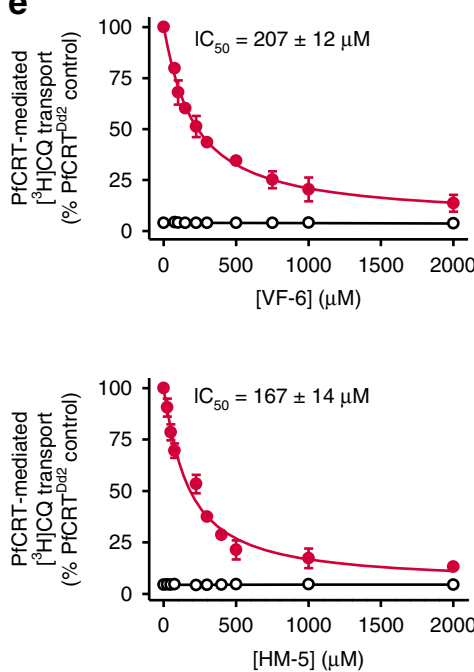

was $\mathrm{pH}$-dependent, but was unaffected by the removal of $\mathrm{Na}^{+}$from the injection buffer (Fig. 2d, e).

The potent trans-stimulatory effects of VF- 6 and HM-5 were concentration-dependent (Fig. 2f). In both cases, the Michaelis constant $\left(K_{\mathrm{m}}\right)$ values increased in the order $\mathrm{PfCRT}^{3 \mathrm{D} 7}<$ PfCRT $^{\text {Ecu } 1110}<$ PfCRT $^{\text {Dd2 }}$ and the maximal velocities $\left(V_{\max }\right)$ decreased in the order $\mathrm{PfCRT}^{3 \mathrm{D} 7}>\mathrm{PfCRT}^{\mathrm{Ecu} 1110}>\mathrm{PfCRT}^{\mathrm{Dd} 2}$.
That is, PfCRT ${ }^{3 \mathrm{D} 7}$ was trans-stimulated at lower peptide concentrations and to a greater extent than the mutant transporters.

The trans-stimulation of $\left[{ }^{3} \mathrm{H}\right] \mathrm{CQ}$ transport by VF-6 was not due to its breakdown into small fragments, as the injection of amino acids, dipeptides or tripeptides derived from VF- 6 failed to trans-stimulate PfCRT. By contrast, all of the VF-6-derived 
Fig. 1 Screening of a solute library for cis-inhibitory activity identified potential substrates of PfCRT. a Schematic showing the cis-inhibition of $\left[{ }^{3} \mathrm{H}\right] \mathrm{CQ}$ uptake via PfCRTDd2 or PfCRTEcu1110 by an unlabelled solute in the Xenopus oocyte system. The library included solutes known to exist in the parasitised erythrocyte, such as vitamins, carbohydrates, metal ions, lipids, amino acids, peptides and other organic and inorganic molecules. $\mathbf{b}$, c The effect on $\left[{ }^{3} \mathrm{H}\right] \mathrm{CQ}$ transport via PfCRT by a subset of solutes $(2 \mathrm{mM})(\mathbf{b})$ or host-derived peptides $(2 \mathrm{mM})(\mathbf{c})$. Non-expressing oocytes and those expressing PfCRT $3 \mathrm{D} 7$ were included as negative controls; these oocytes accumulate a low level of $\left[{ }^{3} \mathrm{H}\right] \mathrm{CQ}$ via simple diffusion of the neutral species ${ }^{15,16}$, reflecting the background level of $\left[{ }^{3} \mathrm{H}\right] \mathrm{CQ}$ transport. Note that aspartate and vitamins $\mathrm{E}$ and B6 caused modest reductions in PfCRTDd2-mediated transport, but only aspartate was found to inhibit PfCRTEcu1110. A diverse range of peptides cause potent inhibition of both PfCRTDd2 or PfCRTEcu1110. $\mathbf{d}$ Heatmap of the cis-inhibition of [3 ${ }^{3}$ ] CQ transport via PfCRTDd2 and PfCRTEcu1110 by 173 different solutes. e VF-6 (top) and HM-5 (bottom) inhibit $\left.{ }^{3} \mathrm{H}\right] \mathrm{CQ}$ transport via PfCRTDd2 in a concentration-dependent manner. The half-maximum inhibitory concentrations (IC 50 ) for VF-6 and HM-5 are $207 \pm 12$ and $167 \pm 14 \mu \mathrm{M}$, respectively. The data are the mean of $n=4$ independent experiments (each yielding similar results and overlaid as individual data points in $\mathbf{b}$ and $\mathbf{c}$ ), and the error is the SEM. Where not visible, the error bars fall within the symbols. The asterisks denote a significant difference from the relevant PfCRTDd2 (red asterisks) or PfCRTEcu1110 (orange asterisks) control; ${ }^{\star} P<0.05,{ }^{\star \star} P<0.01,{ }^{\star \star \star} P<0.001$ (one-way ANOVA). The source datasets are provided as a Source Data file.

peptides containing $\geq 4$ residues trans-stimulated $\left[{ }^{3} \mathrm{H}\right] \mathrm{CQ}$ transport (Supplementary Fig. 1 and Supplementary Data 1,2).

The antiretroviral drug saquinavir has previously been shown to interact with PfCRTDd238. We therefore tested a number of peptide mimics and found that several-including saquinavircis-inhibited and trans-stimulated $\left[{ }^{3} \mathrm{H}\right] \mathrm{CQ}$ transport via PfCRT $^{3 D 7}$, PfCRT Ecul110 and PfCRT ${ }^{\text {Dd2 }}$ (Fig. 2b, c; Supplementary Fig. 1 and Supplementary Data 1,2).

Collectively, these findings indicate that PfCRT transports a broad range of peptides that contain 4-11 amino acid residues, are neutral, negatively or positively charged at $\mathrm{pH} 5.5$ (with a bias towards a net negative charge), and do not have a particular sequence (Supplementary Fig. 1). Furthermore, PfCRT $^{3 \mathrm{D} 7}$ accepts a broader range of peptides than either PfCRTEcul110 or PfCRT ${ }^{\mathrm{Dd}}$; $\left[{ }^{3} \mathrm{H}\right] \mathrm{CQ}$ transport via PfCRT ${ }^{3 \mathrm{D} 7}$ was trans-stimulated by 46 peptides and peptide mimics, which is 9 more than PfCRT $^{\text {Ecul110 }}$, and 20 more than PfCRT ${ }^{\text {Dd2 }}$.

Characterisation of peptide transport via PfCRT. We sought to obtain a direct demonstration of peptide transport via PfCRT by undertaking radioisotope transport assays with one of the potent trans-stimulators of all three PfCRT isoforms. A tritiated analogue of VF-6 was obtained and numerous unsuccessful attempts were made to measure its uptake from the extracellular solution into oocytes expressing PfCRT ${ }^{3 \mathrm{D} 7}$, PfCRT ${ }^{\mathrm{Ecu} 1110}$ or PfCRT Dd2. However, when $\left[{ }^{3} \mathrm{H}\right] \mathrm{VF}-6$ was injected into the oocyte, all three PfCRT isoforms mediated its efflux from the oocyte, whereas $\left[{ }^{3} \mathrm{H}\right]$ VF-6 transport was not detected in the negative controls (Fig. 3a-e). This assay was therefore employed to characterise peptide transport via PfCRT. The efflux of $\left[{ }^{3} \mathrm{H}\right] \mathrm{VF}-6$ from PfCRT-expressing oocytes was linear over time for at least $2 \mathrm{~h}$ and was dependent on both the $\mathrm{pH}$ of the injection buffer and the oocyte membrane potential (see also Supplementary Fig. 2 and Supplementary Note 4). By contrast, removal of $\mathrm{Na}^{+}$or $\mathrm{Cl}^{-}$from the injection buffer, or varying the $\mathrm{Ca}^{2+}$ concentration, was without effect (Supplementary Fig. 2). VF-6 transport via all three PfCRT isoforms was saturable, with $\mathrm{PfCRT}^{3 \mathrm{D} 7}$ having a slightly lower affinity, but much higher capacity, for VF-6 transport relative to the two mutant transporters.

Several drugs known to interact with the substrate-binding cavity of PfCRT were found to inhibit $\left[{ }^{3} \mathrm{H}\right] \mathrm{VF}-6$ transport via the three PfCRT isoforms (Fig. 3f-i; Supplementary Fig. 3). These were verapamil ${ }^{15,39}$ and chlorpheniramine ${ }^{40}$ (both partial reversers of $C Q$ resistance in vitro), the quinine dimer ' $\mathrm{Q}_{2} \mathrm{C}$ ' (currently the most potent inhibitor of $\left.\mathrm{PfCRT}^{\mathrm{Dd} 2}\right)^{20}, \mathrm{CQ}^{15}$ and saquinavir ${ }^{38} \cdot \mathrm{Q}_{2} \mathrm{C}$ was the most potent cis-inhibitor, with half-maximum inhibitory concentrations $\left(\mathrm{IC}_{50}\right)$ in the nanomolar range. With the exception of saquinavir, the drug $\mathrm{IC}_{50} \mathrm{~S}$ decreased in the order PfCRT ${ }^{3 \mathrm{D} 7}>\mathrm{PfCRT}^{\text {Ecu1110 }}>\mathrm{PfCRT}^{\mathrm{Dd} 2}$, and similar $\mathrm{IC}_{50} \mathrm{~s}$ and trends were obtained when verapamil, chlorpheniramine, $\mathrm{CQ}$ and $\mathrm{Q}_{2} \mathrm{C}$ were tested for the ability to trans-inhibit $\left[{ }^{3} \mathrm{H}\right] \mathrm{VF}-6$ transport via PfCRT. By contrast, the saquinavir cis-inhibition $\mathrm{IC}_{50}$ increased in the order PfCRT ${ }^{3 \mathrm{D} 7}<$ $\mathrm{PfCRT}^{\mathrm{Ecu} 1110}<\mathrm{PfCRT}{ }^{\mathrm{Dd} 2}$. Moreover, saquinavir trans-stimulated $\left[{ }^{3} \mathrm{H}\right] \mathrm{VF}-6$ transport via all three PfCRT isoforms. Given this result, and the fact that $\left[{ }^{3} \mathrm{H}\right] \mathrm{CQ}$ is readily taken up into the oocyte from the extracellular solution via PfCRTDd2 and PfCRT Ecu1110, we explored whether high extracellular concentrations of CQ would trans-stimulate, rather than trans-inhibit, the efflux of $\left[{ }^{3} \mathrm{H}\right] \mathrm{VF}-6$. We observed modest trans-stimulation of $\left[{ }^{3} \mathrm{H}\right]$ VF-6 transport via all three PfCRT isoforms when [CQ] $\geq$ $500 \mu \mathrm{M}$.

These findings led us to test whether a subset of the hostpeptides that trans-stimulated CQ transport via PfCRT were likewise able to trans-stimulate $\left[{ }^{3} \mathrm{H}\right] \mathrm{VF}-6$ transport. However, all of the test peptides (including unlabelled VF-6) trans-inhibited $\left[{ }^{3} \mathrm{H}\right]$ VF- 6 transport via PfCRT, whereas the compounds included as negative controls ( $\mathrm{LH}$ and free amino acids) were without effect (Fig. 3j). This result, together with the inability of PfCRT to take up $\left[{ }^{3} \mathrm{H}\right]$ VF- 6 from the external solution, indicated that a cosubstrate is required for peptide transport via PfCRT. All three solutes-peptide, proton and the unidentified co-substrate-must be present on the same side of the membrane for the PfCRTmediated transport of host-derived peptides to occur. The requirement for a co-substrate was unexpected given that the drugs transported by PfCRT-e.g. CQ, quinine, quinidine, quinacrine, methylene blue and saquinavir-only require protons to undergo translocation ${ }^{15,21,39,41}$ (see also Supplementary Note 4). However, the decoupling of some substrates, but not others, from the translocation of a co-substrate is a known phenomenon in carrier-type transporters ${ }^{42-44}$. The co-substrate is evidently present in the oocyte cytosol, but absent from the extracellular buffer. We screened many solutes, including $\mathrm{Fe}^{2+}$, $\mathrm{Fe}^{3+}$ and glutathione, but were unable to identify the co-substrate (Supplementary Data 1). Moreover, re-screening of a range of radiolabelled metabolites as potential substrates via injection into the oocyte failed to detect transport via PfCRT (Fig. 3k), nor were any of these radiolabelled solutes taken up via PfCRT when added to the external solution (Supplementary Fig. 3). Yet within the same assays, $\left[{ }^{3} \mathrm{H}\right] \mathrm{CQ}$ and $\left[{ }^{3} \mathrm{H}\right]$ hypoxanthine were transported (both out of and into the oocyte) via mutant PfCRT and PfNT1, respectively (Fig. 3k; Supplementary Fig. 3i).

Diverse isoforms of PfCRT transport the VF-6 peptide. A broad range of PfCRT isoforms were expressed in the oocyte system (Supplementary Fig. 4). All of the field PfCRT isoforms transported VF-6, albeit to varying degrees (Fig. 4a; the positions of the mutations in PfCRT are shown in Supplementary Fig. 5). The kinetics of VF-6 transport via several of these proteins were indistinguishable from those of $\mathrm{PfCRT}^{3 \mathrm{D} 7}$ (e.g., the 2300, 106/1, 
a

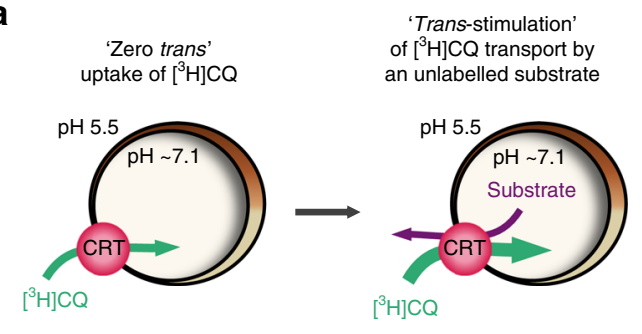

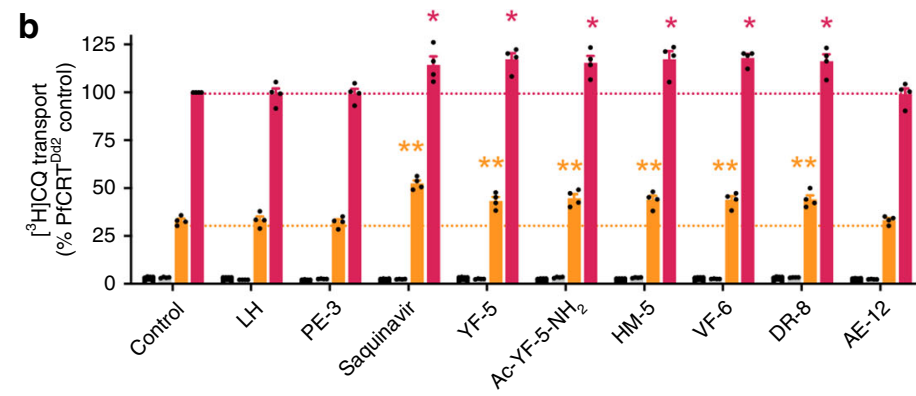

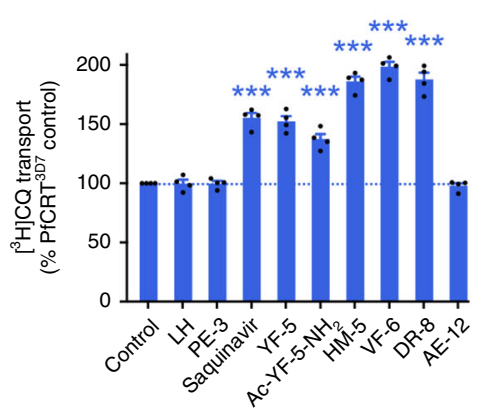

d

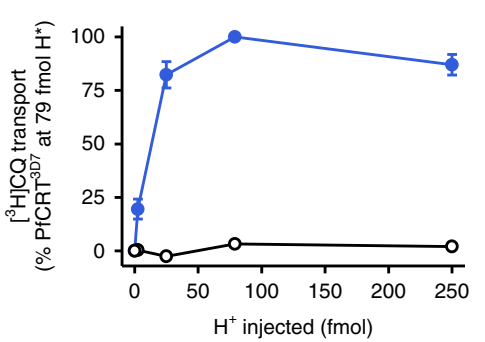

e

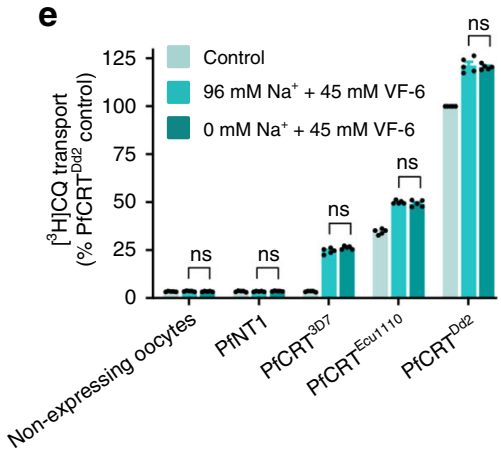

f
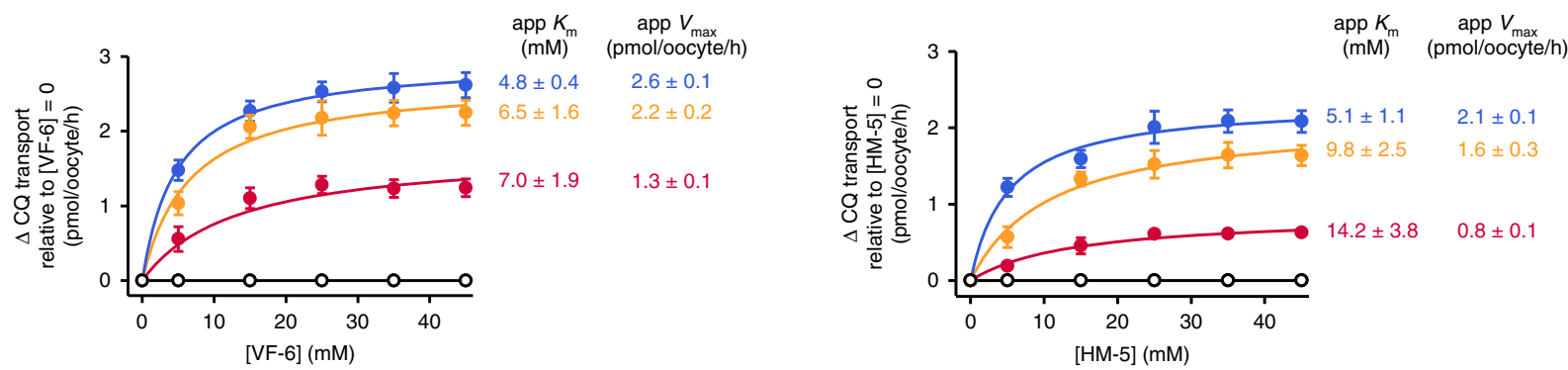

g

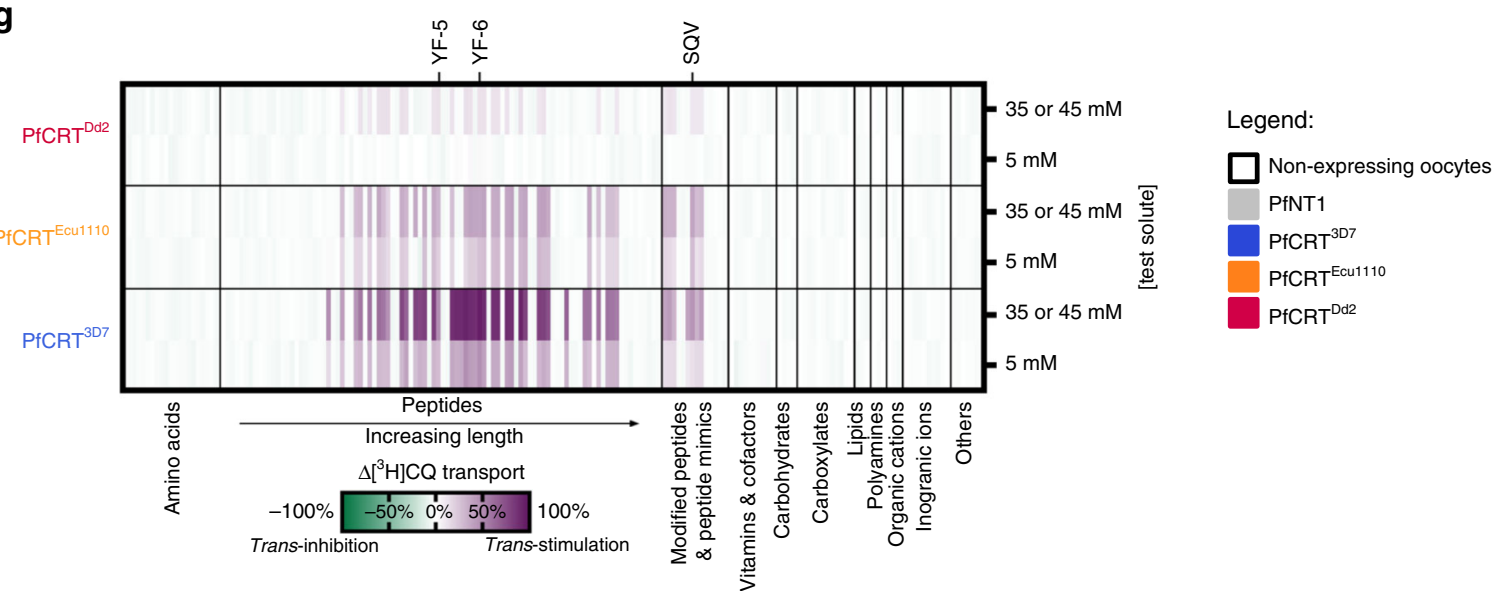

BC22 and Cam738 isoforms), whereas almost all of the CQresistance-conferring isoforms displayed significantly lower capacities for VF-6 transport (e.g., the China e, GB4, 783 and K1 isoforms). Moreover, field isoforms that arose from the introduction of a positively charged residue into a CQ-resistanceconferring variant of PfCRT showed a marked increase in VF-6 transport activity relative to their respective parent isoforms, but had lost the ability to transport CQ (e.g., cf. PfCRT ${ }^{\mathrm{K} 1}$ with PfCRT $106 / 1$ and PfCRT ${ }^{2300}$; Fig. 4a, Supplementary Fig. 6). These findings confirm the importance of electrostatic charges at key positions within PfCRT in determining the transporter's substrate-specificity ${ }^{16,21}$. They also provide a mechanistic explanation for why the re-introduction of a positively charged residue into PfCRT's binding cavity re-sensitises the parasite to CQ while simultaneously restoring its innate fitness 23,45 .

The relationship between the CQ and VF-6 transport activities of field PfCRT isoforms was examined to gain further insights into the correlation between mutations in PfCRT and reduced parasite fitness. The VF-6 transport activity of PfCRT decayed exponentially as its capacity to transport CQ increased (Fig. 4b; Supplementary Fig. 6). That is, a given reduction in peptide transport activity imparts a larger increase in CQ transport activity. A significant outlier to this relationship was PfCRTCam734; its capacity for VF-6 transport exceeded that of 
Fig. 2 PfCRT is trans-stimulated by peptides containing 4-11 amino acid residues. a Schematic showing the trans-stimulation of $\left[{ }^{3} \mathrm{H}\right] \mathrm{CQ}$ transport via PfCRT by an unlabelled substrate in Xenopus oocytes. b, c Trans-stimulation of $\left[{ }^{3} \mathrm{H}\right] \mathrm{CQ}$ transport via PfCRTDd2 or PfCRTEcu1110 (b) or via PfCRT ${ }^{3 D 7}$ (c) by a subset of host-derived peptides and peptide mimics $(45 \mathrm{mM})$. The test solute was injected into the oocyte immediately prior to the commencement of the assay, with the buffer-only and LH treatments serving as injection controls 21 . The negative controls were non-expressing oocytes and those expressing an unrelated $P$. falciparum transporter, the nucleoside transporter 1 (PfNT1 15,76 ). The latter demonstrates that the expression of a similarly sized transporter in Xenopus oocytes does not affect the ability of the oocyte membrane to reseal following injection of a test solute ${ }^{21}$. d Trans-stimulation of $\left[{ }^{3} \mathrm{H}\right] \mathrm{CQ}$ transport via PfCRT $3 \mathrm{D} 7$ by VF-6 $(45 \mathrm{mM}$ ) is $\mathrm{pH}$-dependent, with the largest increase observed when the $\mathrm{pH}$ of the injection buffer was 5.5 (equating to $79 \mathrm{fmoles}^{+}$). e Trans-stimulation of $\left.{ }^{3} \mathrm{H}\right] \mathrm{CQ}$ transport via PfCRT is unaffected by the removal of $\mathrm{Na}^{+}$from the injection buffer. $\mathbf{f}$ Concentrationdependence of the trans-stimulation of $\left[{ }^{3} \mathrm{H}\right] \mathrm{CQ}$ transport via PfCRT by VF-6 (left) and HM-5 (right). The non-expressing oocyte data overlays the data obtained with oocytes expressing PfNT1. $g$ Heatmap of the trans-stimulation of [ $\left.{ }^{3} \mathrm{H}\right] \mathrm{CQ}$ transport via PfCRT3D7, PfCRTEcu1110 or PfCRTDd2 by 173 different solutes. Only peptides and peptide mimics trans-stimulate PfCRT; all other solutes, including aspartate and vitamins E and $\mathrm{B} 6$, failed to increase $\left[{ }^{3} \mathrm{H}\right] \mathrm{CQ}$ transport via PfCRT are thus unlikely to be substrates of the transporter. The data are the mean of $n=4$ independent experiments (each yielding similar results and overlaid as individual data points in $\mathbf{b}, \mathbf{c}$ and $\mathbf{e}$ ), and the error is the SEM. Where not visible, the error bars fall within the symbols. The asterisks denote a significant difference from the relevant PfCRTDd2 (red asterisks), PfCRTEcu1110 (orange asterisks) or PfCRT ${ }^{3 D 7}$ (blue asterisks) buffer-injected control; ${ }^{\star} P<0.05,{ }^{\star \star} P<0.01,{ }^{\star \star \star} P<0.001$, ns: not significant (one-way ANOVA). SQV: saquinavir. The source datasets are provided as a Source Data file.

PfCRT $^{3 \mathrm{D} 7}$, but it also possessed a moderate level of CQ transport activity. This finding is consistent with the observation that parasites expressing PfCRT Cam734 do not display a fitness disadvantage relative to wild-type parasites, and yet are moderately resistant to $\mathrm{CQ}^{46}$.

Three laboratory-derived isoforms that cause a gross enlargement of the $\mathrm{DV}^{13}-\mathrm{L} 272 \mathrm{~F}-\mathrm{PfCRT}^{3 \mathrm{D} 7}$, L272F-PfCRT ${ }^{\mathrm{Dd} 2}$ and C101F-PfCRT Dd2_-displayed unusually low capacities for VF-6 transport (Fig. 4a). This observation provides a molecular basis for understanding why PfCRT is critical for maintaining the normal osmotic pressure and morphology of the DV.

We found that the fusion of polypeptides to the $\mathrm{N}$ - or Ctermini of PfCRT interfere with its natural function. Although only one of the modified PfCRT ${ }^{\mathrm{Dd} 2}$ proteins no longer mediates $\left[{ }^{3} \mathrm{H}\right] \mathrm{CQ}$ transport (Fig. $4 \mathrm{c}$, left panel), all of the tagged versions of PfCRT $^{3 \mathrm{D} 7}$ and PfCRT ${ }^{\mathrm{Dd} 2}$ have lost the ability to transport $\left[{ }^{3} \mathrm{H}\right]$ VF-6 (Fig. 4c, right panel). This observation helps to explain why previous studies, which expressed versions of PfCRT with $\mathrm{N}$ and/or C-terminal fusions, did not delineate the native substrates of PfCRT (Supplementary Note 5).

Peptide mimics are substrates of PfCRT in situ. We sought to verify that PfCRT also functions as a peptide transporter within its native environment of the DV membrane. PfCRT activity was measured using the in situ ' $\mathrm{H}^{+}$-efflux assay' (Fig. 5a) with a set of $P$. falciparum transfectants that are isogenic except for their $p f c r t$ allele. These lines, known as $\mathrm{C} 2{ }^{\mathrm{GC} 03}, \mathrm{C}^{7 \mathrm{G} 8}$ and $\mathrm{C} 4{ }^{\mathrm{Dd} 2}$, express either PfCRT ${ }^{3 D 7}$, PfCRT ${ }^{7 G 8}$ (which harbours the mutations present in PfCRT ${ }^{E c u 1110}$ plus C72S) or PfCRT ${ }^{\mathrm{Dd} 2}$, respectively ${ }^{47}$. The weak-base solute under study enters the parasite's acidic DV via simple diffusion of the neutral species, and/or via transporters such as the multidrug resistance protein 1 (PfMDR $\left.1^{48,49}\right)$, and becomes protonated (Fig. 5a). Peptide mimics and modified hostpeptides (Supplementary Fig. 6) were used in these assays due to their increased membrane permeability, and resistance to proteolytic degradation, relative to natural peptides.

Histidine, ritonavir and lopinavir were without effect in all of the lines, indicating that either they are not substrates of PfCRT, or that insufficient levels of these solutes accumulate within, and are effluxed from, the DV to induce a detectable $\mathrm{H}^{+}$leak. By contrast, several peptides and peptide mimics induced a $\mathrm{H}^{+}$leak in one or more of the parasite lines, consistent with them being substrates of PfCRT. Saquinavir and two modified host-peptides (Ac-YF-5- $\mathrm{NH}_{2}$ and Ac-ST-7- $\mathrm{NH}_{2} ;$ Supplementary Fig. 7) increased the rate of DV alkalinisation in all three lines, with the effect decreasing in the order $\mathrm{C}_{2} \mathrm{GC}^{2} 3>\mathrm{C}^{7 \mathrm{G} 8}>\mathrm{C} 4{ }^{\mathrm{Dd} 2}$. Moreover, leupeptin and E-64 both caused a $\mathrm{H}^{+}$leak in $\mathrm{C} 2^{\mathrm{GC} 03}$ parasites, and leupeptin also induced a $\mathrm{H}^{+}$leak in the
$\mathrm{C}^{7 \mathrm{G} 8}$ line, but neither peptide exerted an effect in $\mathrm{C} 4{ }^{\mathrm{Dd} 2}$. That is, as was observed in the oocyte system, the range of peptides transported decreases in the order $\mathrm{PfCRT}^{3 \mathrm{D} 7}>\mathrm{PfCRT}^{7 \mathrm{G} 8}>$ PfCRT ${ }^{\mathrm{Dd} 2}$.

Verapamil and $\mathrm{Q}_{2} \mathrm{C}$ inhibited the peptide-induced $\mathrm{H}^{+}$leaks in $\mathrm{C} 2{ }^{\mathrm{GC} 03}, \mathrm{C}^{7 \mathrm{G} 8}$ and $\mathrm{C} 4^{\mathrm{Dd} 2}$ parasites (Fig. 5b), providing further evidence that the peptide mimics and modified peptides are exported from the DV via PfCRT. Moreover, as observed in the oocyte system, $\mathrm{Q}_{2} \mathrm{C}$ was the most potent inhibitor, and both $\mathrm{Q}_{2} \mathrm{C}$ and verapamil were more effective against the mutant transporters than against PfCRT ${ }^{3 \mathrm{D}}$.

Kinetic analyses revealed that the peptides increase the rate of DV alkalinisation in a concentration-dependent manner (Fig. 5c; Supplementary Fig. 8), with the capacity for transport decreasing in the order PfCRT ${ }^{3 \mathrm{D} 7}>\mathrm{PfCRT}^{7 \mathrm{G} 8}>\mathrm{PfCRT}^{\mathrm{Dd} 2}$. The same trend was observed in the oocyte system when we measured the concentration-dependence of the trans-stimulation of $\left[{ }^{3} \mathrm{H}\right] \mathrm{CQ}$ transport via PfCRT by these peptides (Fig. 5d; Supplementary Fig. 8), again confirming the strong consensus in the transport properties of PfCRT between the two experimental systems.

The finding that the mutant transporters have reduced capacities for exporting saquinavir suggested that this peptide mimic may be better retained within the DV of CQ-resistant parasites and could thereby affect their sensitivity to this protease inhibitor (which is suspected to exert its weak antimalarial activity inside the DV). We therefore determined the $\mathrm{IC}_{50}$ of saquinavir against the three isogenic lines as well as to CQsensitive (3D7) and CQ-resistant (7G8 and Dd2) strains (Fig. 6, see Supplementary Fig. 8 for parasite susceptibilities to other peptide mimics). As expected, the parasites expressing mutant PfCRT isoforms were more susceptible to saquinavir than those expressing PfCRT $^{3 D 7}$. Moreover, verapamil was shown to increase parasite sensitivity to saquinavir.

Together, these datasets provide a robust demonstration of peptide transport via PfCRT in situ. They also indicated that the reduced capacity of the mutant transporters for exporting hostderived peptides would cause these catabolites to accumulate within the DV.

Parasites with mutant isoforms of PfCRT accumulate peptides. Two previous metabolomic analyses have reported that CQresistant parasites accumulate significantly more aspartate and peptides than their CQ-sensitive counterparts ${ }^{27,50}$. However, it was unclear how to reconcile these metabolite profiles with (1) the inability of PfCRT to translocate amino acids and small peptides and (2) our identification of host-peptide substrates of PfCRT that were not detected, or were reported as non-significant, in these studies. We therefore undertook quantitative peptidomic 
a
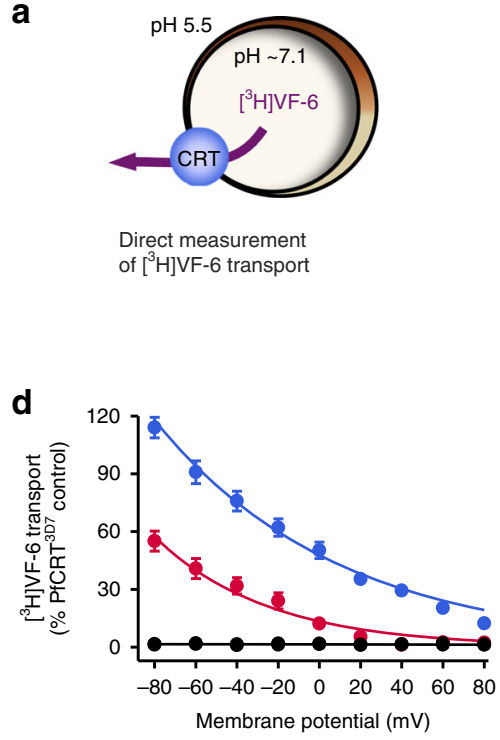

g

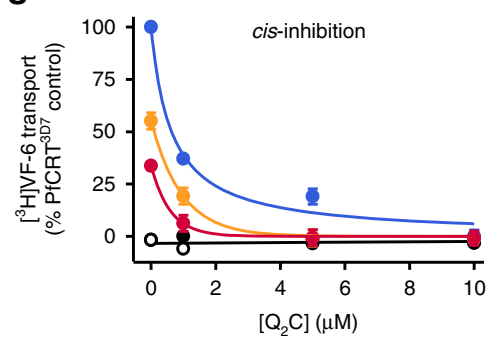

i

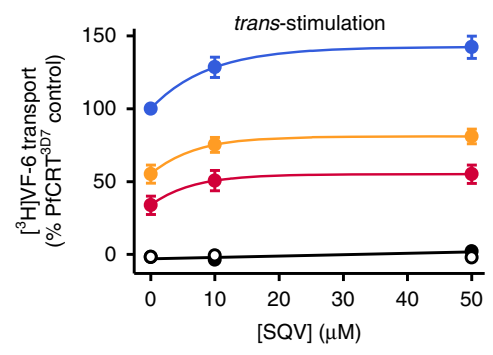

b

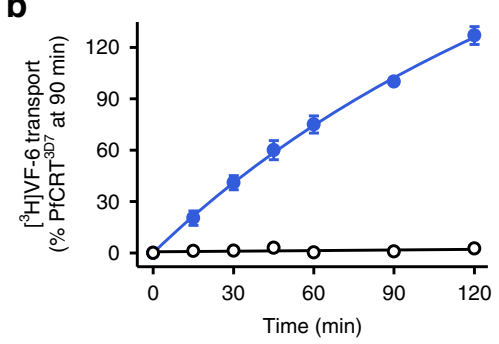

e

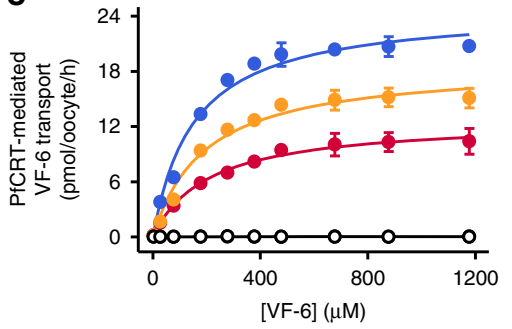

h

\begin{tabular}{llll} 
Drug & \multicolumn{1}{c}{ PfCRT $^{3 D 7}$} & \multicolumn{1}{c}{ PfCRT $^{\text {Ecu1110 }}$} & \multicolumn{1}{c}{ PfCRT $^{\text {Dd2 }}$} \\
\hline VP & $17.5 \pm 1.1$ & $9.5 \pm 1.9^{*}(0.5)$ & $6.8 \pm 1.8^{* *}(0.4)$ \\
CP & $9.8 \pm 0.5$ & $6.2 \pm 0.3^{*}(0.6)$ & $5.0 \pm 1.1^{* *}(0.5)$ \\
CQ & $110 \pm 5.9$ & $72 \pm 3.1^{* *}(0.7)$ & $53 \pm 2.8^{* * *}(0.5)$ \\
Q $C$ & $0.6 \pm 0.02$ & $0.08 \pm 0.007^{* * *}(0.1)$ & $0.01 \pm 0.002^{* * *}(0.02)$ \\
SQV & $50 \pm 2.3$ & $74 \pm 3.9^{* *}(1.5)$ & $89 \pm 3.8^{* * *}(1.78)$
\end{tabular}

j

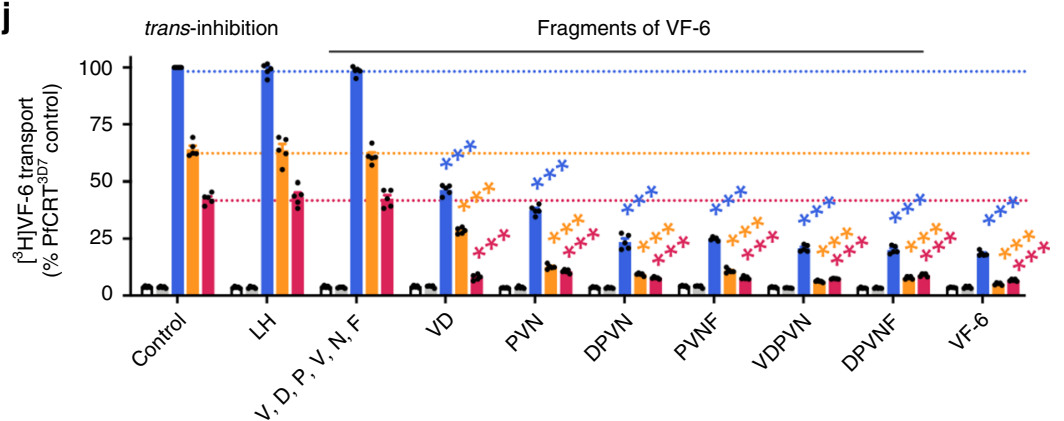

k
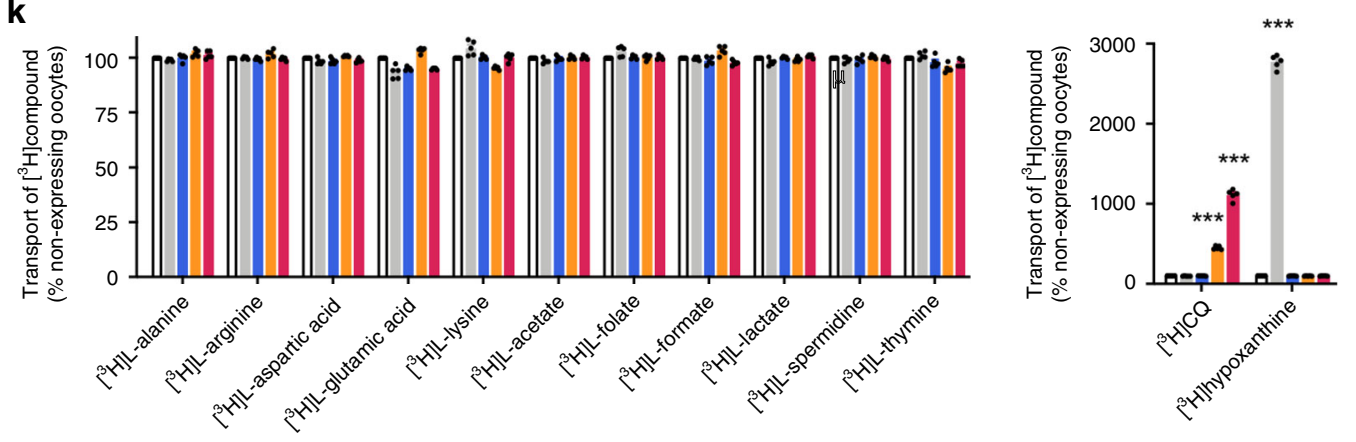

Legend:

$\square$ Non-expressing oocytes

PfNT1

$\mathrm{PfCRT}^{3 \mathrm{D} 7}$ PfCRT ${ }^{\text {Ecu1110 }}$ $\mathrm{PfCRT}^{\mathrm{Dd} 2}$

analyses to examine the populations of host-derived peptides present in the $\mathrm{C} 22^{\mathrm{GC} 03}, \mathrm{C}^{7 \mathrm{G} 8}$ and $\mathrm{C} 4^{\mathrm{Dd} 2}$ parasites (Supplementary Data 3-5). Peptides of varying length, composition and charge were detected, with most originating from haemoglobin and the remainder from other erythrocytic proteins. Several of these peptides accumulated to high levels within the CQ-resistant parasites relative to the $\mathrm{C}_{2} \mathrm{GCO}^{2}$ line (Supplementary Data 3-5), including VF-6 and other peptides we had designated from the trans-stimulation assays as likely substrates of PfCRT.

The apparent agreement between the trans-stimulation and peptidomic datasets for the initial set of peptides studied in the oocyte system led us to test the potential of the accumulation profiles to predict whether a given peptide was a substrate of PfCRT. These predictions also considered the length of the 
Fig. 3 Characterisation of the transport of a host-derived hexapeptide via PfCRT. a Schematic showing the transport of $\left[{ }^{3} \mathrm{H}\right] \mathrm{VF}-6$ via PfCRT in Xenopus oocytes. b-e $\left.{ }^{3} \mathrm{H}\right] \mathrm{VF}-6$ transport via PfCRT is approximately linear with time for at least $2 \mathrm{~h}(\mathbf{b})$, is dependent on both the $\mathrm{pH}$ of the injection buffer (the highest level of transport occurred at $\mathrm{pH} 5.5$, equating to 79 fmoles $\mathrm{H}^{+}$) (c) and the membrane potential (with the rate of VF- 6 efflux steadily decreasing as the membrane potential became more positive) (d), and is saturable (PfCRT ${ }^{3 D 7}$ possesses a slightly lower affinity and higher $V_{\max }$ relative to the mutant transporters) (e). $\left[{ }^{3} \mathrm{H}\right] \mathrm{CQ}$ influx is also dependent on the membrane potential (Supplementary Fig. $2 \mathrm{~g}$ and Supplementary Note 3). $\mathbf{f}, \mathbf{g}$ Cis-inhibition of $\left[{ }^{3} \mathrm{H}\right]$ VF- 6 transport via PfCRT by verapamil (VP) (f) and $\mathrm{Q}_{2} \mathrm{C}(\mathbf{g})$. h The half-maximum inhibitory concentrations $\left(\mathrm{IC}_{50} \mathrm{~S}\right)$ for the cis-inhibition of $\left[{ }^{3} \mathrm{H}\right] \mathrm{VF}-6$ transport via PfCRT by drugs known to interact with the transporter. $\mathbf{i}$ Trans-stimulation of $\left[{ }^{3} \mathrm{H}\right] \mathrm{VF}-6$ transport via PfCRT by saquinavir (SQV). $\mathbf{j}$ Transinhibition of $\left[{ }^{3} \mathrm{H}\right]$ VF- 6 transport via PfCRT by haemoglobin-peptides $(45 \mathrm{mM})$. $\mathbf{k}$ Left: various other radiolabelled solutes are not transported out of the oocyte by PfCRT. Right: in the same assay, $\left[{ }^{3} \mathrm{H}\right] \mathrm{CQ}$ is effluxed via PfCRTEcu1110 and PfCRTDd2 and [ $\left.{ }^{3} \mathrm{H}\right]$ hypoxanthine is effluxed by PfNT1. The data are the mean of $n=5$ independent experiments (each yielding similar results and overlaid as individual data points in $\mathbf{j}$ and $\mathbf{k}$ ), and the error is the SEM. Where not visible, the error bars fall within the symbols. The non-expressing oocyte data overlays the data obtained with oocytes expressing PfNT1 in $\mathbf{b}, \mathbf{c}, \mathbf{e}-\mathbf{g}$ and $\mathbf{i}$. The asterisks denote a significant difference from the relevant PfCRT ${ }^{D d 2}$ (red asterisks), PfCRTEcu1110 (orange asterisks), PfCRT3D7 (blue asterisks) or non-expressing (black asterisks) control; ${ }^{\star} P<0.05,{ }^{\star \star} P<0.01,{ }^{\star \star \star} P<0.001$, ns not significant (one-way ANOVA). The source datasets are provided as a Source Data file.

peptides (i.e. $4-11$ residues) transported by PfCRT. Of the 41 peptides selected for a second round of testing, 22 were predicted to be substrates, 14 were predicted not to be substrates and 5 could not be confidently assigned a prediction from the peptidomic data. All 22 of the predicted substrates transstimulated $\left[{ }^{3} \mathrm{H}\right] \mathrm{CQ}$ transport via PfCRT and all 14 of the predicted non-substrates were without effect. Of the 5 unassigned peptides, one was found to be a PfCRT substrate and the other four failed to trans-stimulate the transporter. We also showed that several of the non-haemoglobin erythrocytic peptides detected in the peptidomic analyses are substrates of PfCRT (Supplementary Data 1 and 2).

Overall, there is a strong positive relationship between the accumulation within CQ-resistant parasites of peptides 4-11 residues in length and their capacity to trans-stimulate PfCRT (Fig. 7). Two types of exceptions to this correlation are outlined in Supplementary Note 6 . These caveats aside, our findings indicate that the peptidomic datasets can be employed to infer which hostderived peptides are likely to be substrates of PfCRT.

The CQ-resistant lines tended to contain lower levels of the large host-derived oligopeptides ( $>15$ residues) relative to the shorter fragments within a given degradation cascade. This is consistent with the digestive process (and thus parasite growth) being slowed down in CQ-resistant parasites in response to an over-accumulation of PfCRT's peptide substrates within the DV.

\section{Discussion}

Our work has provided a definitive resolution of the natural substrates and physiological role of PfCRT, a key contributor to multidrug resistance in the malaria parasite. Contrary to previous reports, PfCRT is not a non-specific transporter of metabolites and/or of organic or inorganic ions. Instead, the datasets we have obtained using a set of complementary in vitro and in situ assays reveal that PfCRT exports host-derived peptides containing 4-11 residues out of the parasite's DV. Peptide transport via PfCRT shows a slight bias towards negatively charged peptides, is saturable at micromolar concentrations, and is blocked by known PfCRT inhibitors, including verapamil, chlorpheniramine and $\mathrm{Q}_{2} \mathrm{C}$. Moreover, the transport of peptides is dependent on protons as well as on a second solute that remains to be identified, but which is naturally present in the Xenopus oocyte. We found that most resistance-conferring isoforms of PfCRT, which efflux CQ from the DV but also typically impart a fitness cost to the parasite, exhibit reduced rates of peptide transport. Furthermore, relative to wild-type PfCRT, the mutant transporters accept a narrower range of peptide substrates.

The significant reductions in the capacities of the mutant proteins to efflux peptides from the DV account for the elevated levels of peptides we measured within CQ-resistant parasites.
Moreover, the relative capacities of different PfCRT isoforms to mediate peptide transport can be readily reconciled with the magnitude of the phenotypes displayed by the corresponding parasites. For example, peptide transport activity decreases in the order PfCRT $^{3 \mathrm{D} 7}>\mathrm{PfCRT}^{7 \mathrm{G} 8}>\mathrm{PfCRT}^{\mathrm{Dd} 2}$ and this mirrors the degree to which peptides of $4-11$ residues accumulate within the respective parasite lines $\left(\mathrm{C} 2^{\mathrm{GC} 03}<\mathrm{C}^{7 \mathrm{G} 8}<\mathrm{C} 4^{\mathrm{Dd} 2}\right)$ as well as the extent of the fitness costs imparted by the mutant transporters ${ }^{51}$. Likewise, a poor capacity for peptide transport correlates with increased osmotic stress (i.e. swollen DVs). That is, the L272F and C101F variants of PfCRT have very low peptide transport activities and cause grossly enlarged DVs, and parasites carrying PfCRT ${ }^{\mathrm{Dd} 2}$, which has one of the poorest capacities for peptide transport amongst the field isoforms of the protein, display moderately swollen DVs.

Our quantitative peptidomic analyses of the $\mathrm{C} 2{ }^{\mathrm{GC} 03}, \mathrm{C}^{7 \mathrm{G} 8}$ and $\mathrm{C} 4{ }^{\mathrm{Dd} 2}$ lines, together with previous metabolomic studies of these parasites ${ }^{27,50}$, point to further metabolic manifestations of the reduced capabilities of mutant isoforms for peptide transport. First, the peptide substrates accumulating within the DV of CQresistant parasites appear to be promiscuously degraded into smaller peptides and amino acids. The generation of these catabolites would add significantly to the osmotic stress of the DV, and this could explain why polymorphisms in a putative amino acid transporter (PfAAT1), a resident of the DV membrane, have been linked to resistance to CQ and other compounds ${ }^{14,52}$. The changes to PfAAT1 likely increase its capacity for exporting amino acids and/or small peptides from the DV. Secondly, the build-up of peptides and amino acids within the DV of CQresistant parasites appear to exert feedback inhibition upon the degradation of host polypeptides, resulting in an accumulation of large oligopeptides relative to the CQ-sensitive line. All of the above perturbations to DV morphology and metabolism, along with our finding that the PfCRT isoforms responsible have significantly reduced capacities for exporting host-derived peptides from this organelle, provide the long-awaited molecular explanations for how CQ-resistance-conferring mutations in PfCRT decrease parasite fitness and why the transporter is essential for parasite survival. Together, our findings indicate that peptide transport via PfCRT serves two roles in the physiology of the intraerythrocytic parasite (Fig. 8). First, the delivery of hostderived peptides to the cytosol provides a source of amino acids to support the parasite's high rates of growth and multiplication. Secondly, the concomitant reduction in peptide levels within the DV prevents the osmotic stress, swelling and dysfunction of this organelle.

The ongoing emergence and spread of new PfCRT isoforms (e.g. in piperaquine-resistant isolates in Cambodia ${ }^{53,54}$ ) indicates that the transporter is still evolving in response to drug pressure. 


\begin{tabular}{|c|c|c|c|c|c|}
\hline \multirow[t]{2}{*}{$\begin{array}{l}\text { PfCRT } \\
\text { isoform }\end{array}$} & Amino acid position in PfCRT & \multicolumn{2}{|c|}{$\begin{array}{c}\text { PfCRT-mediated }\left[{ }^{3} \mathrm{H}\right] \mathrm{VF}-6 \text { transport } \\
\left(\% \mathrm{PfCRT}^{3 \mathrm{D}}\right)\end{array}$} & \multirow[t]{2}{*}{$\underset{(\mu \mathrm{M})}{\operatorname{app} K_{\mathrm{m}}}$} & \multirow[t]{2}{*}{$\begin{array}{l}\operatorname{app} V_{\max } \\
\text { (pmol/oocyte/h) }\end{array}$} \\
\hline & 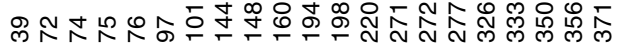 & $25 \quad 50 \quad 75 \quad 100$ & 125 & & \\
\hline $3 \mathrm{D} 7$ & S CMNKHCA L L I E A Q L N N T C I R & & & $231 \pm 6$ & $20 \pm 2$ \\
\hline Cam734 & S C I D T H C F I L T E S E L N NSC I R & & $\therefore * * *$ & $253 \pm 5^{\star * *}$ & $41 \pm 2^{* * *}$ \\
\hline Cam738 & S C I D T H C A I L T E S E L N NSC I R & $\vdots$ & & $228 \pm 4$ & $22 \pm 2$ \\
\hline 2300 & S C I K T H C A L L I E S E L N S T C I I & $\dot{\vdots}$ & & $228 \pm 5$ & $21 \pm 1$ \\
\hline $106 / 1$ & S C I E K H C A L L I E S E L N S T C I I & $\ddot{3}$ & & $229 \pm 3$ & $20 \pm 2$ \\
\hline BC22 & S C I E T H C A L L I K S E L N S T C T I & $\vdots$ & & $226 \pm 5$ & $19 \pm 1$ \\
\hline H209 & S SMNTHCALL I ES Q L N D TR L R & $\therefore *$ & & $211 \pm 3^{*}$ & $14 \pm 3^{*}$ \\
\hline PNG4 & S SMNTHCALL I EA Q L N D T C L R & $\therefore * *$ & & $210 \pm 1^{\star *}$ & $13 \pm 0.8^{* *}$ \\
\hline $7 \mathrm{G} 8$ & S S M N T HCA L L I ESQLNDTCLR & $\therefore * * *$ & & $208 \pm 3^{\star * \star}$ & $13 \pm 0.1^{* \star *}$ \\
\hline $\mathrm{Ph} 2$ & S S M N T H C T L Y I E A Q L N D T C I R & $\ddot{2} * * *$ & & $207 \pm 4^{* * *}$ & $13 \pm 0.2^{* *}$ \\
\hline Ecu1110 & SCMNTHCALL I ESQLNDTCLR & $\therefore * * *$ & & $205 \pm 5^{\star \star \star}$ & $12 \pm 0.1^{* \star *}$ \\
\hline J9 & PC I E A HCA L L I E S E L D S T C T I & $\therefore * * *$ & & $197 \pm 4^{* * *}$ & $11 \pm 0.4^{\star * *}$ \\
\hline Ph1 & S C MNTHCT L Y I E A Q L N D T C I R & 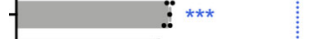 & & $198 \pm 5^{\star * *}$ & $11 \pm 0.8^{\star * *}$ \\
\hline TA6182 & S CMET QCA L L I E S Q L N N TC I I & $\vdots$ :*** & & $197 \pm 4^{* * *}$ & $11 \pm 0.1^{* * *}$ \\
\hline Jav & S CMET QCA L L I E S Q L N N T C I T & $\therefore * * *$ & & $195 \pm 5^{* \star *}$ & $11 \pm 0.2^{* * *}$ \\
\hline China e & S C I E T HCA L L I E S E L N N T C I R & $\because: * * *$ & & $196 \pm 4^{\star \star \star}$ & $11 \pm 0.2^{* * *}$ \\
\hline Dd2 & S C I E THCALL I E S E L N S T C T I & a. $* * *$ & & $171 \pm 5^{\star \star \star}$ & $10 \pm 0.2^{\star \star \star}$ \\
\hline GB4 & S C I E T H C A L L I E S E L N N T C I I & $\because * * *$ & & $168 \pm 3^{* * *}$ & $10 \pm 0.1^{* * *}$ \\
\hline 783 & S C I E T HCA L L I E S E L N N T C T I & $\because * * *$ & & $167 \pm 4^{\star * *}$ & $10 \pm 0.3^{\star * *}$ \\
\hline K1 & S C I E T H C A L L I E S E L N S S T C I I & $\vdots * * *$ & & $166 \pm 5^{\star \star \star}$ & $10 \pm 0.5^{\star * *}$ \\
\hline L272F-PfCRT 3 D7 & SCMNKHCALL I EAQFNNTC I R & 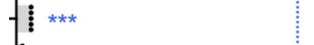 & & $262 \pm 0.0001^{\star \star \star}$ & $3.1 \pm 0.0006^{* * *}$ \\
\hline L272F-PfCRT Dd2 & S C I E T HCALL I E S E F N S T C T I & $* * *$ & & $252 \pm 0.0003^{\star * *}$ & $5.2 \pm 0.0004^{\star * *}$ \\
\hline C101F-PfCRT Dd2 & S C I E THFALL I ESELNSTCT I & $-i$ & & $260 \pm 5^{\star \star \star}$ & $2.8 \pm 0.2^{\star \star \star}$ \\
\hline
\end{tabular}

b

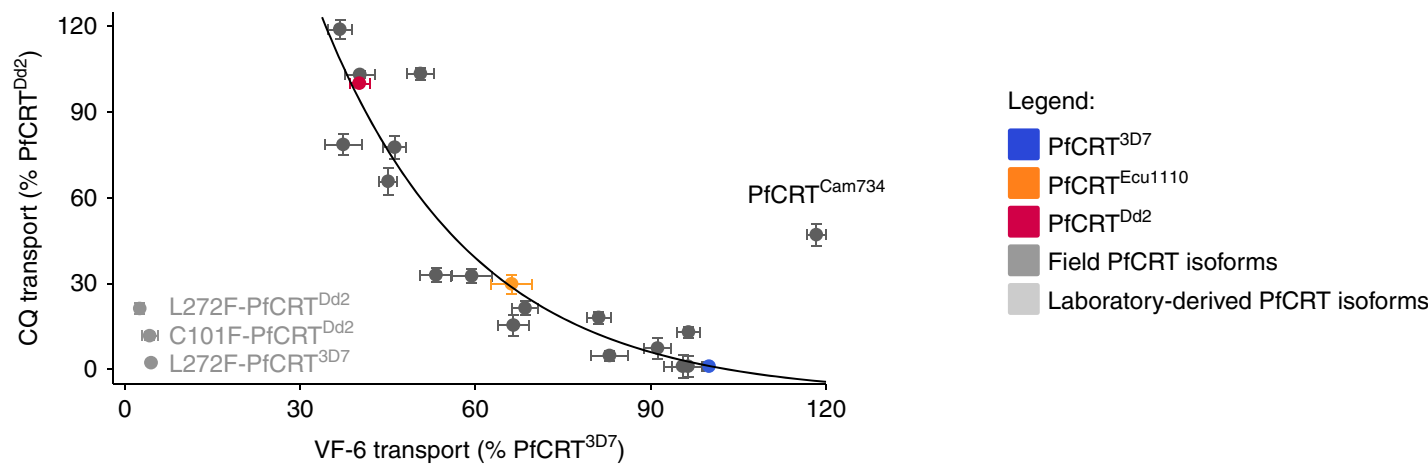

C
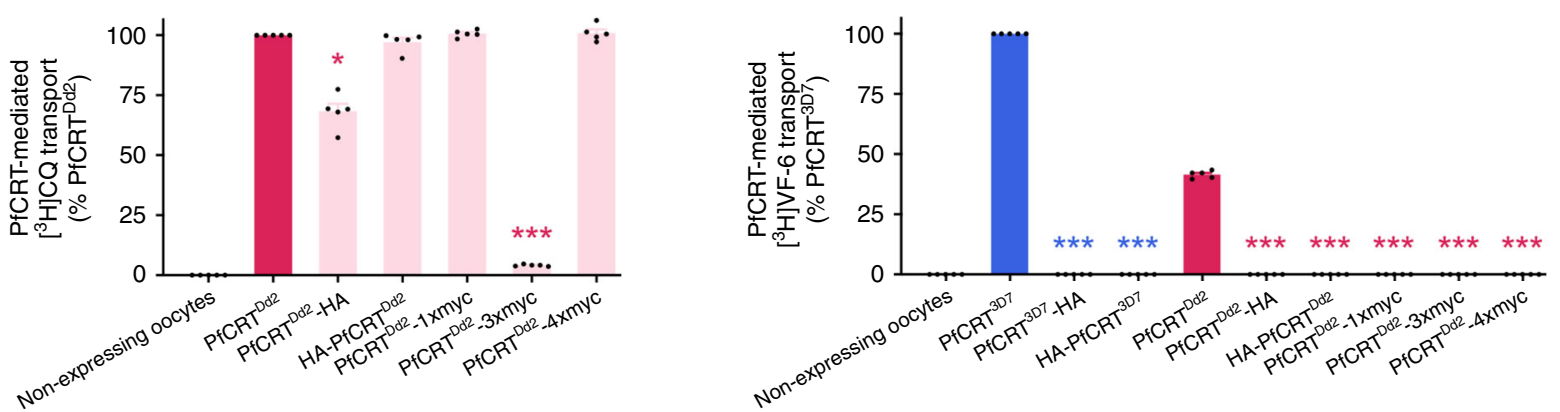

Fig. 4 Diverse field and laboratory-derived isoforms of PfCRT transport the VF-6 peptide. a The VF-6 transport activities, including kinetic parameters, of various field and laboratory-derived PfCRT isoforms in Xenopus oocytes ( $K_{m}$, Michaelis-Menten constant; $V_{\max }$ maximum velocity). $\mathbf{b}$ The capacity of PfCRT to transport VF-6 decays exponentially as the protein's CQ transport activity increases $\left(R^{2}=0.93\right)$. Exceptions to this trend include PfCRTCam734 L272F-PfCRTDd2, L272F-PfCRT3D7 and C101F-PfCRTDd2. c [ $\left.{ }^{3} \mathrm{H}\right] \mathrm{CQ}$ transport (left) and [ $\left.{ }^{3} \mathrm{H}\right]$ VF-6 transport (right) via epitope-tagged versions of PfCRT ${ }^{3 D 7}$ and PfCRT ${ }^{D d 2}$. The version of PfCRT ${ }^{D d 2}$ carrying a C-terminal 3xmyc tag does not mediate $\left[{ }^{3} \mathrm{H}\right] C \mathrm{C}$ transport. The other four variants of PfCRTDd2 retain all or most of their CQ transport activity. By contrast, none of the tagged versions of PfCRT ${ }^{3 D 7}$ or PfCRTDd2 transport [ $\left.{ }^{3} \mathrm{H}\right] \mathrm{VF}-6$. The fusion of polypeptides to PfCRT can therefore abolish its ability to transport peptides, even when the protein remains able to transport CQ. The data are the mean of $n=5$ independent experiments (each yielding similar results and overlaid as individual data points in $\mathbf{a}$ and $\mathbf{c}$ ), and the error is the SEM. Where not visible, the error bars fall within the symbols. The asterisks denote a significant difference from the relevant PfCRTDd2 (red asterisks) or PfCRT ${ }^{3 D 7}$ (blue asterisks) control; ${ }^{\star} P<0.05,{ }^{\star \star} P<0.01,{ }^{\star \star \star} P<0.001$ (one-way ANOVA). The source datasets are provided as a Source Data file. 
a

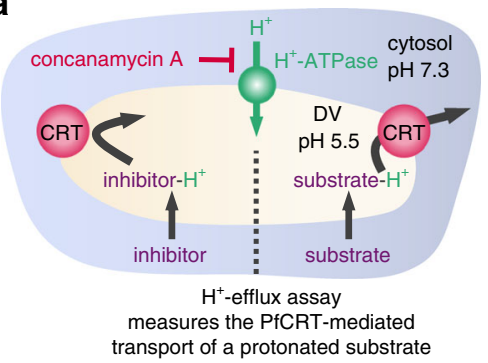

b

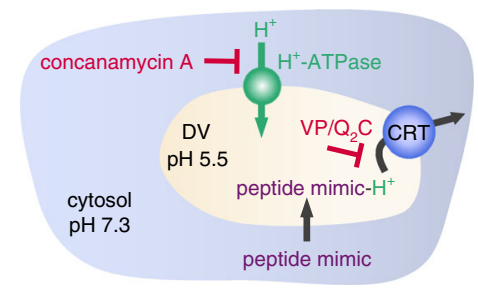

C

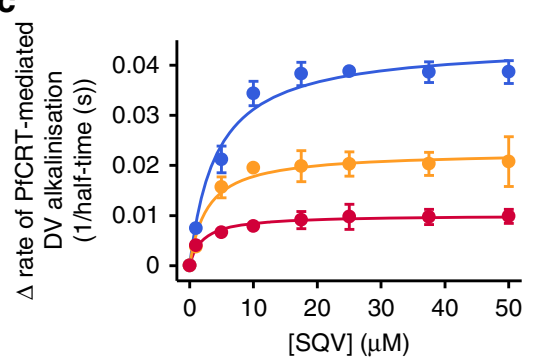

d

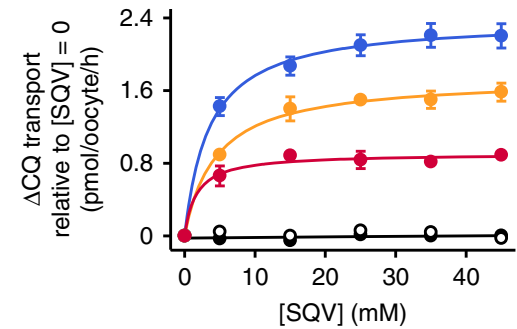

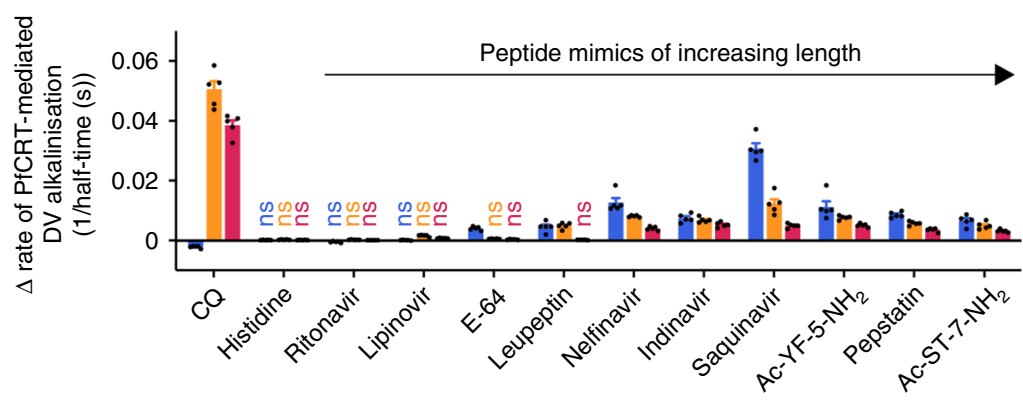
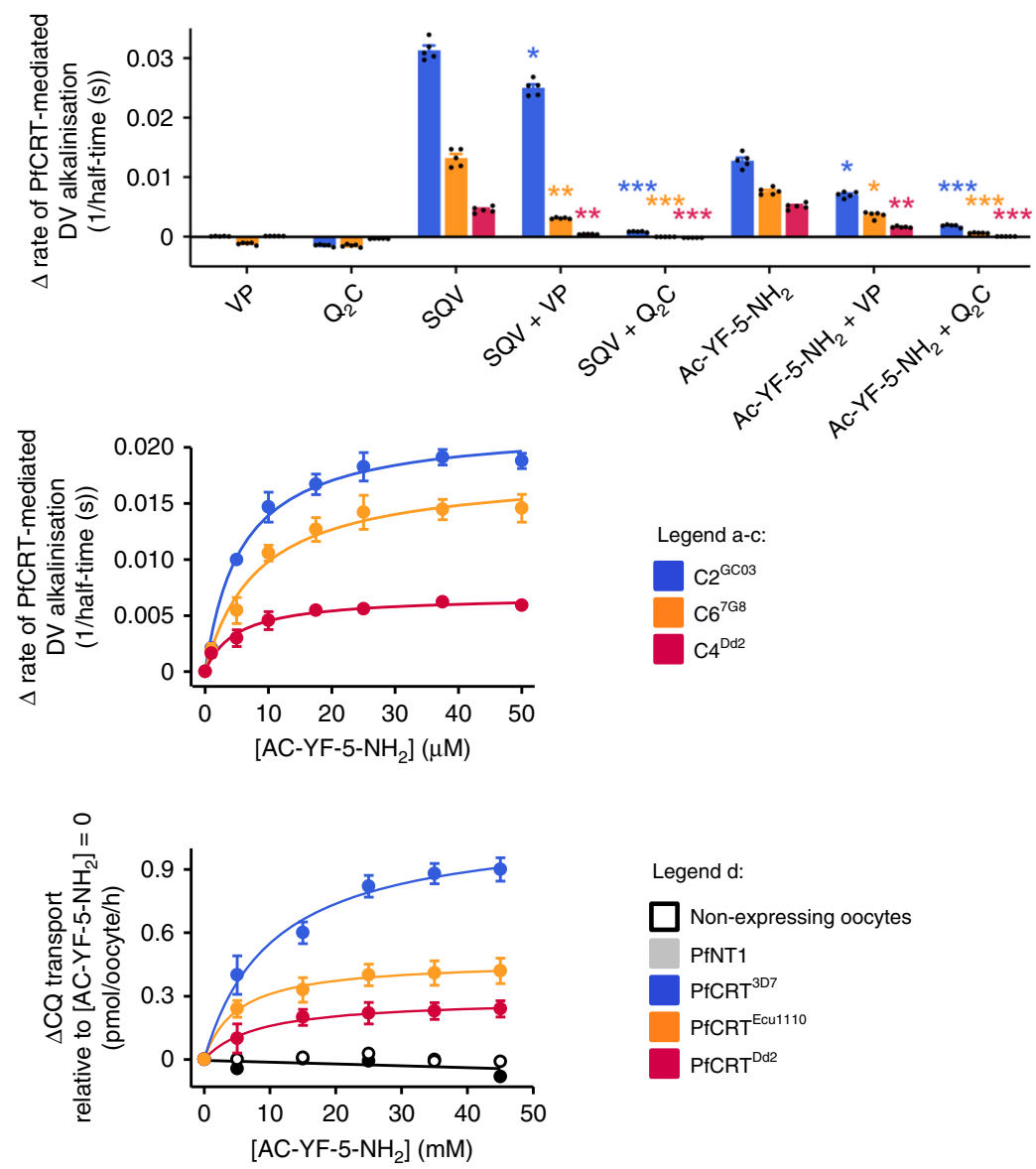

Legend d:

$\square$ Non-expressing oocytes

PfNT1

PfCRT $^{307}$

PfCRT Ecu1110

$\mathrm{PfCRT}^{\mathrm{Dd} 2}$

Fig. 5 Peptide mimics are substrates of PfCRT in situ. a Left: schematic showing the $\mathrm{H}^{+}$-efflux assay. If a protonated solute is a substrate of PfCRT it will cause $\mathrm{H}^{+}$leak when effluxed from the DV. Inhibition of the DV's $\mathrm{H}^{+}$-ATPase by concanamycin A enables this $\mathrm{H}^{+}$leak to be detected (with a pH-sensitive probe) as an increase in the rate of DV alkalinisation. Right: several peptide mimics (10 $\mu \mathrm{M})$ increase the rate of $\mathrm{DV}$ alkalinisation in $\mathrm{C} 2{ }^{\mathrm{GCO}}{ }^{2}, \mathrm{C}^{7 \mathrm{G} 8}$ and $\mathrm{C} 4 \mathrm{Dd} 2$ parasites. $\mathrm{CQ}$ (the positive control) causes the rate of DV alkalinisation to increase in the $\mathrm{C} 6^{7 \mathrm{G} 8}$ and $\mathrm{C} 4{ }^{\mathrm{Dd} 2}$ lines and to decrease slightly in $\mathrm{C} 2 \mathrm{GCO} 3$ parasites. This is consistent with previous applications of the $\mathrm{H}^{+}$-efflux assay ${ }^{36,37}$ and with the abilities of PfCRTECu1110, PfCRT ${ }^{7 G 8}$ and PfCRTDd2 (but not $\mathrm{PfCRT}^{3 \mathrm{D} 7}$ ) to transport $\mathrm{CQ}$ when tested under normal conditions in the oocyte system ${ }^{15,16}$. Unless labelled ns, $P<0.05$ relative to the absence of a test solute. $\mathbf{b}$ Left: schematic showing the inhibition of PfCRT by verapamil (VP) or the quinine dimer $\mathrm{Q}_{2} \mathrm{C}_{\text {in }}$ the $\mathrm{H}^{+}$-efflux assay. Right: the increase in the rate of DV alkalinisation caused by saquinavir (SQV; $10 \mu \mathrm{M})$ and Ac-YF-5- $\mathrm{NH}_{2}(10 \mu \mathrm{M})$ is inhibited by $\mathrm{VP}(50 \mu \mathrm{M})$ and $\mathrm{Q}_{2} \mathrm{C}(1 \mu \mathrm{M})$. The statistical analyses were performed relative to the SQV or Ac-YF-5- $\mathrm{NH}_{2}$ controls. c SQV (left) and Ac-YF-5- $\mathrm{NH}_{2}$ (right) increase the rate of DV alkalinisation in a concentration-dependent manner. d Concentration-dependence of the trans-stimulation of $\left[{ }^{3} \mathrm{H}\right] \mathrm{CQ}$ transport via PfCRT by SQV (left) and Ac-YF-5-NH ${ }_{2}$ (right) in Xenopus oocytes. The non-expressing oocyte data overlays the data obtained with oocytes expressing PfNT1. The data are the mean of $n=5$ independent experiments (each yielding similar results and overlaid as individual data points in $\mathbf{a}$ and $\mathbf{b}$ ), and the error is the SEM. Where not visible, the error bars fall within the symbols. The asterisks denote a significant difference from the relevant $\mathrm{C} 4 \mathrm{Dd} 2$ (red asterisks), $\mathrm{C}^{7 \mathrm{G} 8}$ (orange asterisks) or $\mathrm{C} 2{ }^{\mathrm{GCO}} 3$ (blue asterisks) control; ${ }^{\star} P<0.05,{ }^{\star \star} P<0.01,{ }^{\star \star \star} P<0.001$, ns: non-significant (one-way ANOVA). The source datasets are provided as a Source Data file.

A point of concern in this regard is PfCRT ${ }^{\text {Cam734, }}$, as its peptide transport capability is superior to that of the wild-type protein, yet it has retained the ability to transport CQ. We now have the means to evaluate both the peptide and drug transport functions of these new isoforms and thereby gain significant insights into the causes and constraints that are dictating the evolution of PfCRT in different malarious regions. Moreover, the knowledge we have gained of PfCRT's native substrates, of its ability to transport-and affect the antiplasmodial activity of -peptide mimics, as well as of the inhibition of its natural function by existing drugs, provides a foundation for the development of strategies that combat malaria parasites by targeting 
a

\begin{tabular}{lllll} 
Parasite & \multicolumn{2}{c}{$\mathrm{CQIC}_{50}(\mathrm{nM})$} & \multicolumn{2}{c}{$\mathrm{SQV} \mathrm{IC}_{50}(\mu \mathrm{M})$} \\
line/strain & Control & $+1 \mu \mathrm{M} \mathrm{VP}$ & \multicolumn{1}{c}{ Control } & $+1 \mu \mathrm{M} \mathrm{VP}$ \\
\hline $\mathrm{C}^{\mathrm{GC} 03}$ & $27 \pm 1.6$ & $26 \pm 1.3$ & $6.8 \pm 0.4$ & $5.1 \pm 0.2^{* *}$ \\
$\mathrm{C}^{7 \mathrm{G} 8}$ & $87 \pm 2.1$ & $25 \pm 0.2^{* * *}$ & $4.2 \pm 0.4$ & $2.3 \pm 0.3^{* *}$ \\
$\mathrm{C} 4^{\mathrm{Dd} 2}$ & $149 \pm 4.6$ & $26 \pm 0.1^{* * *}$ & $3.5 \pm 0.5$ & $1.9 \pm 0.1^{* *}$ \\
\hline 3D7 & $25 \pm 1.1$ & $24 \pm 0.9$ & $7.4 \pm 0.3$ & $5.9 \pm 0.6^{* *}$ \\
$7 \mathrm{G} 8$ & $94 \pm 4.4$ & $28 \pm 1.6^{* * *}$ & $4.7 \pm 0.1$ & $2.2 \pm 0.1^{* *}$ \\
$\mathrm{Dd} 2$ & $151 \pm 4.8$ & $25 \pm 1.0^{* * *}$ & $3.3 \pm 0.2$ & $2.1 \pm 0.3^{* *}$
\end{tabular}

b

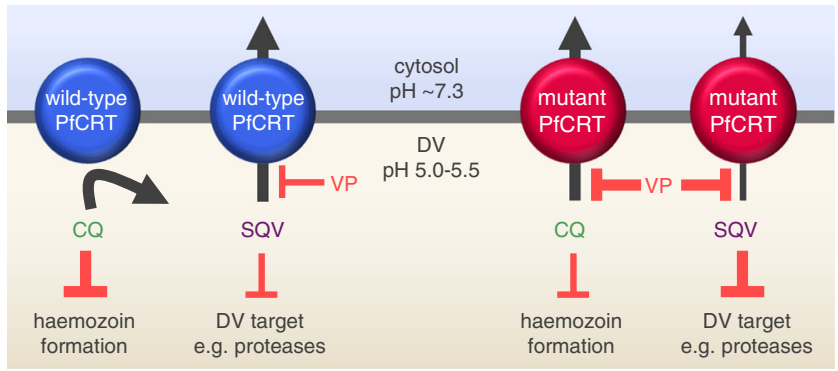

Fig. 6 CQ-resistance-conferring isoforms of PfCRT increase parasite susceptibility to saquinavir. a The antiplasmodial activities of $C Q$ and saquinavir (SQV) against $\mathrm{CQ}$-sensitive $\left(\mathrm{C}^{\mathrm{GCO}}{ }^{\mathrm{C}}\right.$ and $\left.3 \mathrm{D} 7\right)$ and $\mathrm{CQ}$ resistant $\left(\mathrm{C}^{7 \mathrm{G} 8}, \mathrm{C} 4 \mathrm{Dd} 2,7 \mathrm{G} 8\right.$ and $\left.\mathrm{Dd} 2\right)$ parasites in the presence or absence of verapamil (VP). The data are the mean of $n=5$ independent experiments (each yielding similar results) and the error is the SEM. The asterisks denote a significant difference from the relevant control (red asterisks, $\mathrm{C} 4{ }^{\mathrm{Dd} 2}$ or $\mathrm{Dd} 2$ control; orange asterisks, $\mathrm{C} 6^{7 \mathrm{G} 8}$ or $7 \mathrm{G} 8$ control; blue asterisks, $\mathrm{C}^{\mathrm{GCO}}$ or $3 \mathrm{D} 7$ control); ${ }^{\star \star} P<0.01,{ }^{\star \star \star} P<0.001$, ns: nonsignificant (one-way ANOVA). The source datasets are provided as a Source Data file. b Mechanistic model for the increased susceptibility of CQ-resistant parasites to SQV. PfCRT ${ }^{3 D 7}$ (wild-type PfCRT) lacks detectable CQ transport activity, whereas the CQ-resistance-conferring isoforms of PfCRT (mutant PfCRT) efflux CQ from the DV. VP inhibits CQ transport via the mutant transporters, thereby re-sensitising the CQresistant parasites to this antimalarial drug. By contrast, $\mathrm{PfCRT}{ }^{3 \mathrm{D} 7}$ has a greater capacity for transporting SQV out of the DV than do the mutant isoforms. Moreover, it is the wild-type protein that confers reduced sensitivity to SQV. Given that VP (1) inhibits SQV transport via both the wild-type and mutant PfCRT transporters and (2) increases the antiplasmodial activity of SQV in all of the parasite types, our findings indicate that SQV acts on a target within the DV.

both the normal and drug-resistance-conferring functions of PfCRT.

\section{Methods}

Xenopus laevis frogs. Ethical approval of the work performed with female X. laevis frogs was obtained from the Australian National University (ANU) Animal Experimentation Ethics Committee (Animal Ethics Protocol Numbers R.BSB.01.10 and A2013/13) in accordance with the Australian Code of Practice for the Care and Use of Animals for Scientific Purposes. The frogs were purchased from Nasco (Cat\# LM00535M) and were housed in the Xenopus Frog Facility of the ANU Research School of Biology in compliance with the relevant institutional and Australian Government regulations.

Culture of parasitised erythrocytes. The use of human blood for this work was approved by the ANU Human Research Ethics Committee (Human Ethics Approval Numbers 2011/266 and 2017/351). The asexual intraerythrocytic stages of three $P$. falciparum strains and three $P$. falciparum $p f c r t$ transfectant lines were used in this study. The strains were wild-type ' $3 \mathrm{D} 7$ ' parasites (isolated from the Netherlands but probably of African origin ${ }^{55}$ ) and the CQ-resistant parasites 'Dd2' (isolated from Southeast Asia) and '7G8' (isolated from Brazil). The three pfcrt transfectant lines, generated by Sidhu et al. ${ }^{47}$, were $\mathrm{C}_{2} \mathrm{GC} 03$ (a recombinant control that retains the wild-type $p f c r t$ allele, $\mathrm{PfCRT}^{3 \mathrm{D} 7}$ ) and the CQ-resistant lines $\mathrm{C}^{7 \mathrm{G} 8}$ and $\mathrm{C} 4{ }^{\mathrm{Dd} 2}$ (in which the wild-type pfcrt allele of the 'GC03' line has been replaced with the allele from the $7 \mathrm{G} 8$ or Dd2 strain, respectively ${ }^{47}$ ). A PCR error in the generation of the $\mathrm{C}^{7 \mathrm{G} 8}$ line introduced an additional mutation (I351M) which is not normally found in the $p f c r t$ allele of 7G8 parasites ${ }^{56}$. The parasite cultures were maintained at $4 \%$ haematocrit and synchronised with $5 \%(\mathrm{w} / \mathrm{v})$ sorbitol ${ }^{57}$. The $p f c r t$ transfectant lines were maintained in the presence of the selection agents blasticidin (5 $\mu$ M; Sigma-Aldrich) and WR99210 ( $5 \mathrm{nM}$; Jacobus Pharmaceuticals). These selection agents were not present during the experiments.

Two cell line authentication methods were used to verify the identities of the six strains and lines used in this study. The first evaluated the CQ-resistance phenotype of each parasite culture by performing cell proliferation assays, thereby yielding CQ $\mathrm{IC}_{50} \mathrm{~s}$ for each parasite type. The results were verified by comparing them to previously published data ${ }^{21,36,37}$ (see the $P$. falciparum proliferation assay section below for details). Mycoplasma detection assays were also performed periodically on each of the six parasite cultures using PCR in conjunction with a primer mix that amplifies ribosomal DNA from different mycoplasma strains $s^{58}$. No mycoplasma infections were detected in any of the parasite cultures throughout the course of this study.

PfCRT coding sequences and CRNA synthesis. The coding sequences of each of the PfCRT isoforms were generated via site-directed mutagenesis ${ }^{16}$ using the primers listed in Supplementary Data 6. The DNA template was a codonharmonised sequence of PfCRT that had been inserted into the pGEM-He-Juel oocyte expression vector ${ }^{59}$. This sequence encodes a version of PfCRT that is free of endosomal-lysosomal trafficking motifs and thus results in the expression of the transporter at the plasma membrane of Xenopus oocytes ${ }^{15,16}$. The plasmids were linearised with SalI (ThermoFisher Scientific) from which $5^{\prime}$ capped complementary RNA (cRNA) was synthesised using the mMessage mMachine T7 transcription kit (Ambion), and then purified with the MEGAclear kit (Ambion).

Isolation and injection of Xenopus oocytes. Adult female frogs were anaesthetised in a solution of ethyl 3-aminobenzoate methanesulfonate salt (SigmaAldrich) and $1 \mathrm{mM} \mathrm{NaHCO}$ (Sigma-Aldrich) ${ }^{41}$. Sections of the ovary were removed and the collagenous membrane encasing the oocytes was degraded by collagenase A and collagenase D (Sigma-Aldrich) ${ }^{41}$. Stage V-VI oocytes were microinjected with cRNA ( $20 \mathrm{ng}$ per oocyte) encoding a PfCRT isoform or PfNT1, and were stored at $16-18{ }^{\circ} \mathrm{C}$ in $\mathrm{OR}^{2+}$ buffer supplemented with $50 \mu \mathrm{g} / \mathrm{mL}$ penicillin and streptomycin.

Transport assays using Xenopus oocytes. The orientation of PfCRT in the parasite's DV membrane, and also in the oocyte plasma membrane, is such that its $\mathrm{N}$ - and C-termini extend into the cytosol. The oocytes were suspended in a reaction buffer adjusted to $\mathrm{pH} 5.5$ to mimic the $\mathrm{pH}$ of the DV lumen ${ }^{1,2}$. In this scenario, the transport of a substrate via PfCRT from the acidic extracellular solution into the oocyte cytosol ${ }^{15}$ is analogous to the parasite's PfCRT-mediated efflux of a substrate from the acidic DV and into the cytosol ${ }^{15}$. Unless specified otherwise, this is the direction in which substrate transport was measured in the oocyte assays.

The radiolabelled compounds were purchased from either Pharmaron $\left(\left[{ }^{3} \mathrm{H}\right] \mathrm{VF}-\right.$ 6, $23 \mathrm{Ci} / \mathrm{mmol})$, American Radiolabelled Chemicals $\left(\left[{ }^{3} \mathrm{H}\right] \mathrm{CQ}, 20 \mathrm{Ci} / \mathrm{mmol}\right)$, PerkinElmer (e.g., $\left[{ }^{3} \mathrm{H}\right] \mathrm{L}$-aspartate and $\left[{ }^{3} \mathrm{H}\right]$ hypoxanthine monochloride), Amersham Biosciences $\left(\left[{ }^{3} \mathrm{H}\right]\right.$ acetate and $\left[{ }^{3} \mathrm{H}\right]$ folate) or ICN Pharmaceuticals $\left(\left[{ }^{3} \mathrm{H}\right]\right.$ thymine). All of the host-derived peptides were custom-synthesised (GenScript; see Supplementary Data 1 and 2 for peptide sequences).

Unless specified otherwise, the transport assays were conducted over $1.5 \mathrm{~h}$ at $27.5^{\circ} \mathrm{C}$ and the reaction buffer was ND96 $(96 \mathrm{mM} \mathrm{NaCl}, 2 \mathrm{mM} \mathrm{KCl}, 1 \mathrm{mM} \mathrm{MgCl}$, $1.8 \mathrm{mM} \mathrm{CaCl}_{2}, 10 \mathrm{mM}$ MES and $10 \mathrm{mM}$ Tris-base) at $\mathrm{pH} 5.5$.

Measurements of the cis-inhibition of $\left[{ }^{3} \mathrm{H}\right] \mathrm{CQ}$ transport via PfCRT ${ }^{\mathrm{Dd} 2}$ or PfCRT Ecul110 by a test solute (data presented in Fig. 1 and Supplementary Data 1,2 ) were performed on oocytes three days post-cRNA-injection ${ }^{15,21}$. Ten oocytes were washed twice with the relevant ND96 buffer. The assay commenced with the addition of ND96 buffer supplemented with $0.25 \mu \mathrm{M}\left[{ }^{3} \mathrm{H}\right] \mathrm{CQ}, 15 \mu \mathrm{M}$ unlabelled CQ, and the unlabelled solute under study (at a concentration specified in the figure legends and Supplementary Data 1,2). The assay was terminated by removing the reaction buffer and washing the oocytes with ice-cold ND96 buffer. The oocytes were lysed in $10 \%(\mathrm{w} / \mathrm{v})$ sodium dodecyl sulfate (SDS) and the radioactivity accumulated within each oocyte was measured with a MicroBeta ${ }^{2}$ microplate liquid scintillation analyser (PerkinElmer)

The $\mathrm{IC}_{50}$ values presented in Fig. 1e were determined in SigmaPlot Windows Version 11.0 by a least-squares fit of the equation $y=y_{\min }+\left[\left(y_{\max }-y_{\min }\right) /(1+\right.$ ([test compound]/IC $\left.\left.{ }_{50}\right)^{c}\right]$ ) to the data, where $y$ is PfCRT-mediated CQ transport, $y_{\min }$ and $y_{\max }$ are the minimum and maximum values of $y$, and $c$ is a fitted constant. The PfCRT-mediated CQ transport presented in Supplementary Fig. 5 was calculated by subtracting the level of $\left[{ }^{3} \mathrm{H}\right] \mathrm{CQ}$ accumulation that was detected in the negative control oocytes (non-expressing oocytes and oocytes expressing PfCRT $^{3 D 7}$ ) from that measured in oocytes expressing PfCRTDd2 or PfCRTEcul110 At least four independent experiments were performed (on different days and using oocytes from different frogs), and within each experiment measurements were made from ten oocytes per treatment. 


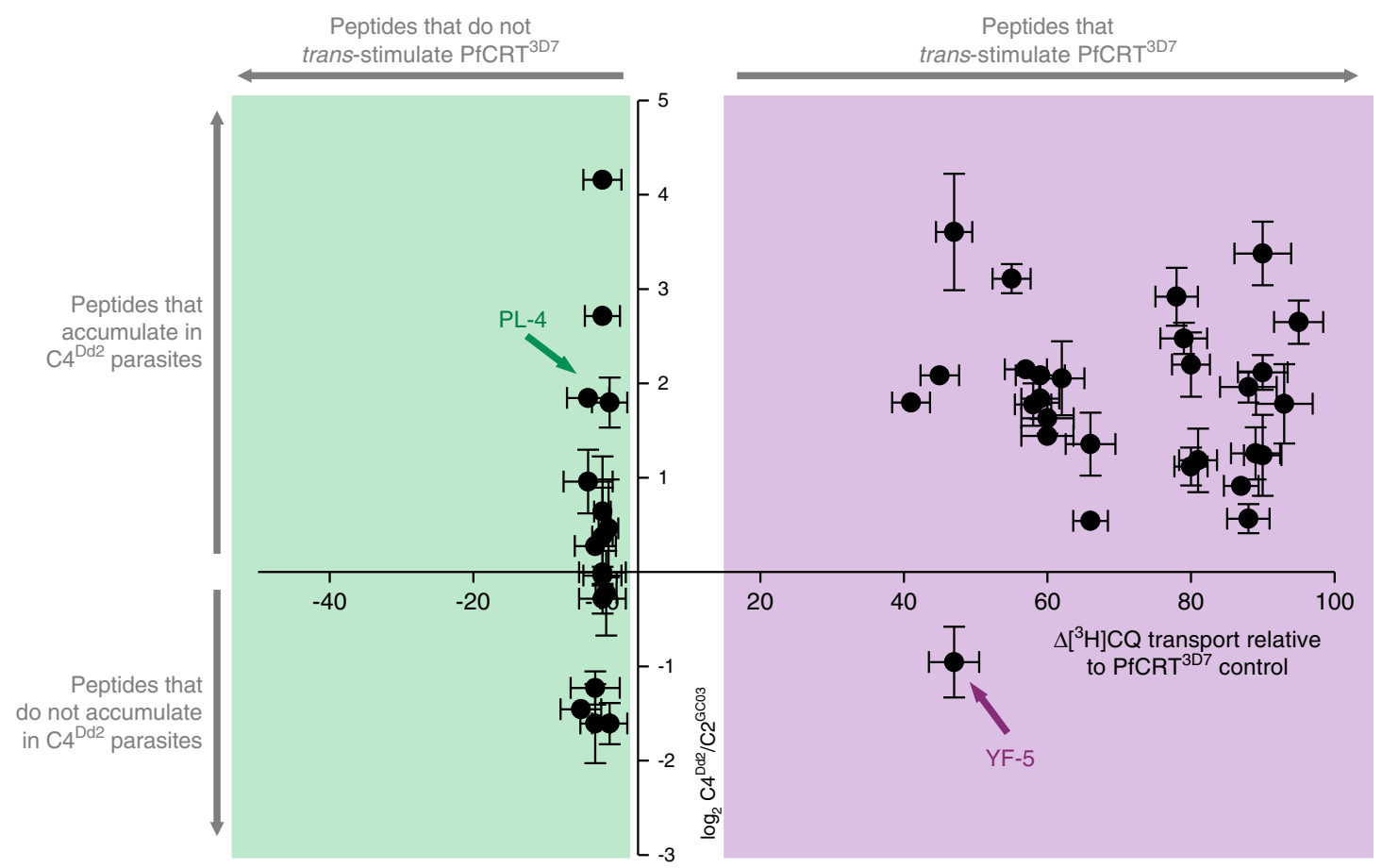

Fig. 7 The peptide substrates of PfCRT accumulate in parasites expressing mutant isoforms of the transporter. Host-derived peptides in erythrocytes infected with $\mathrm{C}_{2} \mathrm{GCO}$ or $\mathrm{C}_{4}{ }^{\mathrm{Dd} 2}$ parasites were quantified using tandem liquid-chromatography mass-spectrometry and the peptide levels within the $\mathrm{C} 4 \mathrm{Dd} 2$ line were expressed relative to those measured in the $\mathrm{C}_{2} \mathrm{GCO} 3$ parasites (Supplementary Data 3 and 5). For peptides containing 4-11 residues, a positive relationship exists between the ability to trans-stimulate CQ transport via PfCRT $3 \mathrm{D} 7$ and accumulation within the CQ-resistant $\mathrm{C} 4 \mathrm{Dd} 2$ parasites. The analysis used the PfCRT ${ }^{3 D 7}$ trans-stimulation dataset, rather than that generated for PfCRT ${ }^{D d 2}$, because the peptides most likely to accumulate in the $\mathrm{C} 4^{\mathrm{Dd} 2}$ line will include those that are very poor substrates of (or no longer transported by) PfCRT ${ }^{\mathrm{Dd} 2}$. An analysis of the data with a Bayesian Information Criteria model identified two distinct populations. The trans-stimulation data are the mean of four independent experiments (each yielding similar results) and the peptide accumulation data are the mean of 2-6 independent experiments (each yielding similar results). Error bars are shown for data points that are $n \geq 3$; the $Y$ error is the SD and the $X$ error is the SEM. The source datasets are provided as a Source Data file.

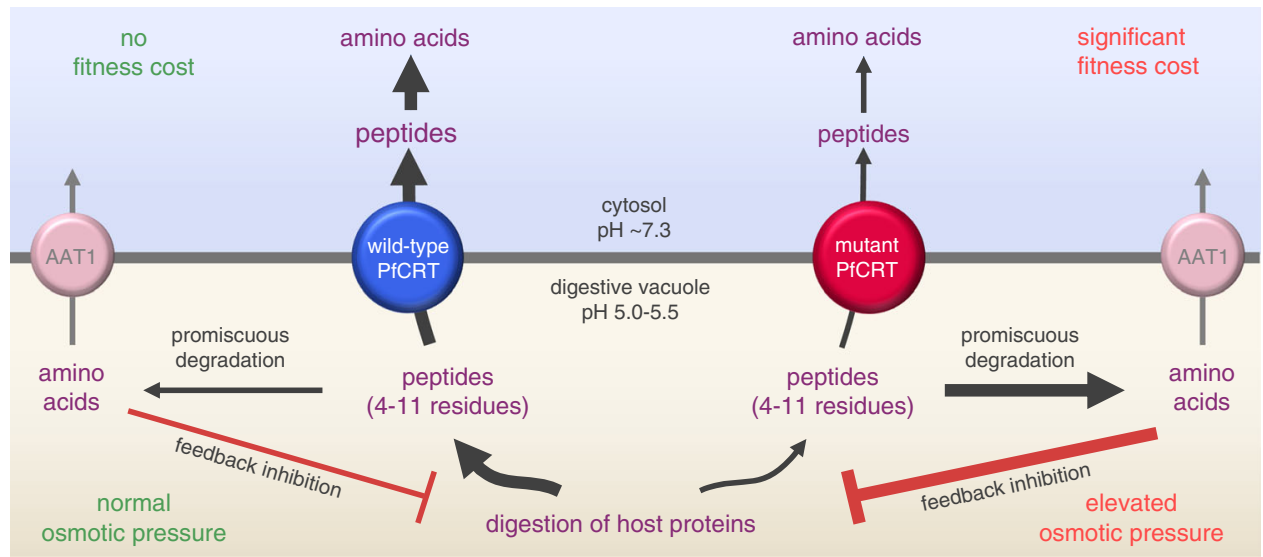

Fig. 8 Model for the natural function and physiological role of PfCRT. PfCRT transports host-derived peptides 4-11 residues in length, and of varying composition and charge, out of the DV and into the parasite's cytosol. Wild-type PfCRT transports a broader range of peptides, and has a higher capacity for peptide transport, than most CQ-resistance-conferring isoforms of PfCRT. The diminished abilities of the mutant transporters to efflux peptides results in the accumulation of these peptides within CQ-resistant parasites. Moreover, the promiscuous degradation of the accumulated peptides leads to the build-up of small peptide fragments and amino acids, which exerts further osmotic pressure upon the DV and causes feedback inhibition of the digestion of host proteins. PfCRT therefore serves two roles: (1) it prevents osmotic stress of the DV by exporting peptides and (2) it delivers these peptides to the cytosol where they are degraded into amino acids to fuel parasite growth. AAT1: amino acid transporter 1.

The ability of an unlabelled test solute to trans-stimulate [ $\left.{ }^{3} \mathrm{H}\right] \mathrm{CQ}$ transport via PfCRT (Figs. 2, 5d; Supplementary Fig. 1 and Supplementary Data 1,2) was measured using oocytes two days post-cRNA-injection ${ }^{21}$. The oocytes were injected with $25 \mathrm{~nL}$ of an unlabelled solute (to achieve estimated intracellular concentrations of $5-45 \mathrm{mM}$ ) or a control treatment (ND96 buffer $\mathrm{pH} 5.5$ or the dipeptide LH; the estimated intracellular concentration of LH was $45 \mathrm{mM}$ ). The intracellular concentrations were calculated using previous estimates of the volume of stage V-VI oocytes $\left(\sim 400 \mathrm{~nL}^{60}\right)$. A subset of experiments measured the $\mathrm{pH}$-dependence of the trans-stimulatory effect of VF-6 on $\left[{ }^{3} \mathrm{H}\right] \mathrm{CQ}$ uptake via PfCRT. The oocytes were injected with VF-6 suspended in $25 \mathrm{~nL}$ ND96 buffer adjusted to $\mathrm{pH} 5.0,5.5,6.0$ or 7.0, which corresponded to the injection of $2.5-250 \mathrm{fmol}$ of $\mathrm{H}^{+}$. The $\mathrm{Na}^{+}$-dependence of the trans-stimulatory effect of VF-6 was assessed by injecting the oocytes with VF-6 suspended in ND96 buffer (pH 5.5) or a $\mathrm{Na}^{+}$-free version of this buffer 
(the $\mathrm{Na}^{+}$was replaced with choline). The transport of $\left[{ }^{3} \mathrm{H}\right] \mathrm{CQ}$ was measured as described above.

For the data presented in Figs. $2 \mathrm{f}$ and $5 \mathrm{~d}$, the rate of CQ transport above that measured in the relevant buffer-injected control was calculated. A least-squares fit of the Michaelis-Menten equation $\left(v=V_{\max }[\right.$ substrate $] /\left(K_{\mathrm{m}}+\right.$ [substrate] $\left.)\right)$ was then fitted to the data in SigmaPlot Windows Version 11.0 to derive the kinetic parameters for the trans-stimulation of $\left[{ }^{3} \mathrm{H}\right] \mathrm{CQ}$ transport by an unlabelled substrate. At least four independent experiments were performed (on different days and using oocytes from different frogs), and within each experiment measurements were made from ten oocytes per treatment.

A total of 95 peptides derived from either haemoglobin or other erythrocytic proteins were tested in the cis-inhibition and trans-stimulation assays. These tests were conducted in two phases: peptides that were screened before the peptidomic datasets were obtained and those which were selected for study on the basis of these datasets. The first round of testing consisted of 54 peptides that were predicted by an in silico analysis to be generated from human haemoglobin by the parasiteencoded proteases present within the DV. The known cleavage sites of these proteases were plotted within the $\alpha$ - and $\beta$-haemoglobin sequences to yield peptide fragments that were likely to exist in the $\mathrm{DV}^{61-66}$. The second round of testing was performed with 41 peptides that were selected from the peptidomic datasets as candidate substrates or non-substrates of PfCRT. These experiments were undertaken to determine if the peptidomic results could be used to predict whether a given host-derived peptide is likely to be a substrate of PfCRT.

The characterisation of $\left[{ }^{3} \mathrm{H}\right] \mathrm{VF}-6$ transport via 23 different field and laboratory-derived isoforms of PfCRT was undertaken with oocytes two days post-cRNA-injection (Figs. 3a-j, 4; Supplementary Fig. 2). The oocytes were injected with $25 \mathrm{~nL}$ of ND96 buffer ( $\mathrm{pH}$ 5.5) supplemented with $\left[{ }^{3} \mathrm{H}\right] \mathrm{VF}-6$ and unlabelled VF- 6 to achieve estimated intracellular concentrations of 1.4 and $200 \mu \mathrm{M}$, respectively. Ten oocytes that had resealed at the injection site were transferred to a $5 \mathrm{~mL}$ polystyrene round bottom tube (In Vitro Technologies) and washed with $3.5 \mathrm{~mL}$ of ND96 buffer before being transferred to separate wells of a white 96-well plate (PerkinElmer). This treatment served to establish the amount of radioactivity within the oocytes immediately prior to the commencement of the transport assay. Another 10 resealed oocytes were transferred to a $5 \mathrm{~mL}$ tube and washed with $3.5 \mathrm{~mL}$ of ND96 buffer. The assay commenced with the addition of $100 \mu \mathrm{L}$ of ND96 buffer and the oocytes were incubated at $27.5^{\circ} \mathrm{C}$ for $1.5 \mathrm{~h}$ (unless specified otherwise; Fig. $3 \mathrm{~b}$ ). The assay was terminated by removing the reaction buffer with a pipette and washing the oocytes twice with $3.5 \mathrm{~mL}$ of ice-cold ND96 buffer. Each oocyte was transferred to a separate well of a white 96-well plate. The oocytes were lysed by the addition of $20 \mu \mathrm{L}$ of $10 \%(\mathrm{w} / \mathrm{v})$ SDS and overnight incubation at room temperature. The lysed oocyte was then combined with $150 \mu \mathrm{L}$ of MicroScint- 40 microscintillant (PerkinElmer), the plate covered with a TopSeal-A (PerkinElmer), and the radioactivity measured with a MicroBeta ${ }^{2}$ microplate liquid scintillation analyser (PerkinElmer). VF-6 transport was calculated by subtracting the amount of radioactivity (measured in counts per minute) present within the oocytes at the end of the incubation from that measured in the oocytes sampled immediately before the commencement of the assay. The $\mathrm{pH}$-dependence of transport (Fig. 3c) was determined by injecting the oocytes with $\left[{ }^{3} \mathrm{H}\right] \mathrm{VF}-6$ suspended in $25 \mathrm{~nL}$ ND96 buffer adjusted to $\mathrm{pH} 5.0,5.5,6.0$ or 7.0 , which corresponded to the injection of 2.5-250 $\mathrm{fmol}$ of $\mathrm{H}^{+}$. The dependence of $\left[{ }^{3} \mathrm{H}\right] \mathrm{VF}-6$ transport on $\mathrm{Na}^{+}$or $\mathrm{Cl}^{-}$was examined by injecting the oocytes with $\left[{ }^{3} \mathrm{H}\right] \mathrm{VF}-6$ suspended in the control ND96 buffer (pH 5.5) or a version of this buffer that lacked either $\mathrm{Na}^{+}$or $\mathrm{Cl}^{-}$(Supplementary Fig. 2). $\mathrm{Na}^{+}$ was replaced with $96 \mathrm{mM}$ of $\mathrm{KCl}$ and $\mathrm{Cl}^{-}$was replaced with gluconate salts of $\mathrm{Na}^{+}\left(\mathrm{NaC}_{6} \mathrm{H}_{11} \mathrm{O}_{7} ; 96 \mathrm{mM}\right), \mathrm{K}^{+}\left(\mathrm{KC}_{6} \mathrm{H}_{11} \mathrm{O}_{7} ; 2 \mathrm{mM}\right), \mathrm{Mg}^{2+}\left(\mathrm{MgC}_{12} \mathrm{H}_{22} \mathrm{O}_{14}\right.$; $1 \mathrm{mM})$ and $\mathrm{Ca}^{2+}\left(\mathrm{CaC}_{12} \mathrm{H}_{22} \mathrm{O}_{14} ; 1.8 \mathrm{mM}\right)$. The dependence of peptide transport on $\mathrm{Ca}^{2+}$ was determined by injecting the oocytes with $\left[{ }^{3} \mathrm{H}\right] \mathrm{VF}-6$ suspended in ND96 buffers that contained different concentrations of $\mathrm{Ca}^{2+}(0-5 \mathrm{mM}$; Supplementary Fig. 2). The dependence of $\left[{ }^{3} \mathrm{H}\right] \mathrm{CQ}$ transport on $\mathrm{Na}^{+}, \mathrm{Cl}^{-}$or $\mathrm{Ca}^{2+}$ were conducted by suspending the oocytes in the aforementioned ND96 buffers and measuring the uptake of $\left[{ }^{3} \mathrm{H}\right] \mathrm{CQ}$ transport into the oocyte. The dependence of PfCRT-mediated transport on the membrane potential was examined by using (1) $\mathrm{Na}^{+}$ionophore III in conjunction with the $\mathrm{Na}^{+}$gradients listed in Supplementary Data 7 and (2) $\mathrm{Cl}^{-}$ionophore III in conjunction with the $\mathrm{Cl}^{-}$gradients listed in Supplementary Data 7 to clamp the membrane potential of the oocyte from -80 to $+80 \mathrm{mV}$. Both the efflux of $\left[{ }^{3} \mathrm{H}\right] \mathrm{VF}-6$ from the oocyte (Fig. 3d) and the influx of $\left[{ }^{3} \mathrm{H}\right] \mathrm{CQ}$ into the oocyte (Supplementary Fig. 2g) were measured under these conditions. Analyses of the kinetics of VF-6 transport via PfCRT (Figs. 3e and 4a) were undertaken by injecting the oocytes with ND96 buffer pH 5.5 supplemented with $\left[{ }^{3} \mathrm{H}\right] \mathrm{VF}-6$ (to achieve an estimated intracellular concentration of $1.4 \mu \mathrm{M}$ ) and unlabelled VF-6 (to achieve estimated intracellular concentrations between $0-1150 \mu \mathrm{M}$ ). The kinetic parameters for VF-6 transport via different isoforms of PfCRT (Figs. 3e and 4a) were determined in SigmaPlot Windows Version 11.0 by a least-squares fit of the Michaelis-Menten equation to the data.

A subset of assays measured the ability of solutes known to interact with PfCRT to either cis-inhibit, trans-inhibit or trans-stimulate $\left[{ }^{3} \mathrm{H}\right] \mathrm{VF}-6$ transport. These experiments involved adding these solutes to either the cis- or trans-side of the membrane relative to $\left[{ }^{3} \mathrm{H}\right] \mathrm{VF}-6$. The $\mathrm{IC}_{50}$ values presented in Fig. $3 \mathrm{~h}$ and Supplementary Fig. 2 were determined in SigmaPlot Windows Version 11.0 by a least-squares fit of the equation $y=y_{\min }+\left[\left(y_{\max }-y_{\min }\right) /\left(1+\left([\text { compound }] / \mathrm{IC}_{50}\right)^{c}\right]\right)$ to the data, where $y$ is PfCRT-mediated VF- 6 transport, $y_{\min }$ and $y_{\max }$ are the minimum and maximum values of $y$ and $c$ is a fitted constant. At least five independent experiments were performed (on different days and using oocytes from different frogs), and within each experiment measurements were made from ten oocytes per treatment.

Measurements of the uptake or efflux of a number of other radiolabelled compounds (Fig. 3k; Supplementary Fig. 3) were performed using the methods described above for $\left[{ }^{3} \mathrm{H}\right] \mathrm{CQ}$ and $\left[{ }^{3} \mathrm{H}\right] \mathrm{VF}-6$, respectively.

Western blot analyses. Semiquantitative measurements of the level of PfCRT protein in the oocyte membrane were performed using an established Western blot protocol ${ }^{16}$ and with oocytes three days post-cRNA-injection. Briefly, the proteins present in the oocyte membrane preparations were separated on a 4-12\% NuPAGE Bis-Tris SDS-polyacrylamide gel (ThermoFisher Scientific) and transferred to a $0.45 \mu \mathrm{M}$ nitrocellulose blotting membrane (Amersham, GE Healthcare Life Sciences). The membranes were probed with rabbit anti-PfCRT antibody (concentration of 1:4000; GenScript) followed by horseradish peroxidase-conjugated goat anti-rabbit antibody (1:8000; ThermoFisher Scientific). Validation of the specificity of the anti-PfCRT antibody has been published in detail elsewhere ${ }^{16}$ The band for each PfCRT isoform was detected with Supersignal West Pico Chemiluminescent reagent (Pierce), quantified using the Image J software ${ }^{67}$, and expressed as a percentage of the intensity measured for the $\mathrm{PfCRT}^{3 \mathrm{D} 7}$ band. Total protein staining was used to evaluate sample loading and efficiency of transfer ${ }^{16}$. At least five independent experiments were performed (using oocytes from different frogs), and in each experiment measurements were averaged from two separate replicates.

Immunofluorescence assays. An immunofluorescence assay was used to localise PfCRT in oocytes three days post-cRNA-injection ${ }^{21}$. The oocytes were fixed with $4 \%(\mathrm{v} / \mathrm{v})$ paraformaldehyde and permeabilised with $100 \%$ methanol. After a series of incubations in blocking solutions, the oocytes were first incubated with the rabbit anti-PfCRT antibody (1:100; GenScript), and then with the Alexa Fluor 488 donkey anti-rabbit antibody (1:500; ThermoFisher Scientific). The oocytes were embedded in an acrylic resin using the Technovit 7100 plastic embedding system (Kulzer). A microtome was used to obtain $\sim 4 \mu \mathrm{m}$ slices of the oocytes, which were mounted on microscope slides. Images of the slices were obtained with a Leica $\mathrm{Sp} 5$ inverted confocal laser microscope (Leica Microsystems) using the $\times 63$ objective. Excitation was achieved with a $488 \mathrm{~nm}$ argon laser and the emissions were captured using a 500-550 nm filter. Images were acquired using the Leica Application Suite Advanced Fluorescence software (Leica Microsystems). At least two independent experiments were performed (on oocytes from different frogs) for each oocyte type within which slices were examined from at least five oocytes. All of the slices taken from oocytes expressing a PfCRT isoform displayed a fluorescent band above the pigment layer (i.e. consistent with the localisation of PfCRT to the plasma membrane) that was not present in non-PfCRT-expressing oocytes.

P. falciparum $\mathbf{H}^{+}$-efflux assays. Saponin-isolated trophozoite-stage parasites containing the membrane-impermeant $\mathrm{pH}$-sensitive fluorescent indicator fluorescein-dextran (10,000 MW; Life Technologies) in their DVs were prepared using a lysis-and-resealing technique that has been detailed elsewhere ${ }^{36,37}$. Trophozoite-stage parasites were isolated with saponin and suspended in a saline solution ( $125 \mathrm{mM} \mathrm{NaCl}, 5 \mathrm{mM} \mathrm{KCl}, 1 \mathrm{mM} \mathrm{MgCl} 2,20 \mathrm{mM}$ glucose, $25 \mathrm{mM}$ HEPES; $\mathrm{pH} 7.1$ ) at a density of $1 \times 10^{7}$ cells $/ \mathrm{mL}$. The fluorometry experiments were performed as outlined previously ${ }^{37}$. The $\mathrm{pH}$ of the DV was monitored at $37^{\circ} \mathrm{C}$ using a PerkinElmer Life Sciences LS50B fluorometer with a dual excitation Fast Filter accessory (excitation wavelengths 490 and $450 \mathrm{~nm}$; emission wavelength 520 $\mathrm{nm})$. The experiments entailed monitoring the alkalinisation of the DV upon the addition of the V-type $\mathrm{H}^{+}$-ATPase inhibitor concanamycin A (100 nM; SigmaAldrich), in the presence or absence of the test solutes. Half-times for the rate of DV alkalinisation were determined in SigmaPlot Windows Version 11.0 by a leastsquares fit of the equation $F=F_{0}+F_{\max } /\left[1+\left(t / t_{1 / 2}\right)^{c}\right]$, where $F$ is the fluorescence ratio, $F_{0}$ is the initial fluorescence ratio (averaged over $20 \mathrm{~s}$ immediately prior to opening the chamber of the fluorometer and adding the concanamycin A), $t$ is time, $t_{1 / 2}$ is the half-time for DV alkalinisation, $F_{\max }$ is the maximal change in fluorescence ratio and $c$ is a fitted constant ${ }^{36}$. The rate of PfCRT-mediated DV alkalinisation was calculated by subtracting the rate of DV alkalinisation of the solvent control from that of each treatment within each parasite line (Fig. $5 \mathrm{a}-\mathrm{c}$; Supplementary Fig. 8). In all cases, five independent experiments were performed on different days.

P. falciparum proliferation assays. Parasite proliferation was measured in 96-well plates using a fluorescent DNA-intercalating dye ${ }^{68,69}$. Synchronous ring-stage parasite cultures ( $\sim 1 \%$ haematocrit and $1 \%$ parasitaemia) were incubated with different concentrations of the test compound for $72 \mathrm{~h}$ at $37^{\circ} \mathrm{C}$ and under reduced $\mathrm{O}_{2}$ conditions. The assay was terminated by freezing and thawing the samples, after which $100 \mu \mathrm{L}$ of SYBR Safe DNA Gel Stain (Molecular Probes; $0.2 \mu \mathrm{L} / \mathrm{mL}$ ) in a lysis buffer $(20 \mathrm{mM}$ Tris-HCl, $5 \mathrm{mM}$ EDTA, $0.008 \%(\mathrm{w} / \mathrm{v})$ saponin and $0.08 \%(\mathrm{v} / \mathrm{v})$ Triton X-100; $\mathrm{pH}$ 7.5) was added to each well. The fluorescence from each well was 
measured using a Tecan Infinite M1000 PRO microplate reader (excitation wavelength $490 \mathrm{~nm}$; emission wavelength $520 \mathrm{~nm}$ ). The fluorescence values for the wells containing the highest concentration of the compound were averaged and this value was then subtracted from each of the well values obtained for that 96-well plate. The level of parasite proliferation in the presence of each compound concentration was expressed as a percentage of the proliferation measured in the absence of the compound. The $\mathrm{IC}_{50} \mathrm{~s}$ were determined in SigmaPlot Windows Version 11.0 by a least-squares fit of the equation $y=a /\left[1+\left([\text { compound }] / \mathrm{IC}_{50}\right)^{c}\right]$ to the data, where $y$ is the percent parasite proliferation, $a$ is the maximum change in the percent parasite proliferation, and $c$ is a fitted constant. In all cases, five independent experiments were performed (on different days), and within each experiment measurements were averaged from three replicates.

P. falciparum peptidomic analyses. The isogenic lines $\mathrm{C} 2^{\mathrm{GC} 03}, \mathrm{C}^{7 \mathrm{G} 8}$ and $\mathrm{C} 44^{\mathrm{Dd} 2}$ were maintained at the same developmental stage via sorbitol synchronisation. At the trophozoite-stage, $P$. falciparum-infected erythrocytes were enriched $(>95 \%$ parasitaemia) via magnetic separation (Colebrook Bioscience) and incubated at $37^{\circ} \mathrm{C}$ for $1 \mathrm{~h}$ prior to metabolite extraction (to ensure recovery). Two peptide analyses were conducted, one for smaller peptides $(<8 \mathrm{mer})$ and one for larger peptides ( $>8 \mathrm{mer}$ ). Cell density was estimated by haemocytometer and $1 \times 10^{8}$ and $6 \times 10^{8}$ cells were used per sample for the small and large peptide analyses, respectively. The cell suspension was transferred into a microcentrifuge tube $(2 \mathrm{~mL})$ and metabolites/endogenous peptides were extracted using $80 \%(\mathrm{v} / \mathrm{v})$ acetonitrile or $90 \%(\mathrm{v} / \mathrm{v})$ methanol for the small or large peptide analyses, respectively ${ }^{70}$. Following centrifugation, the supernatants were collected and stored at $-80^{\circ} \mathrm{C}$ until further processing commenced.

Detection and quantification of polar metabolites including endogenous small peptides (typically $<8$ mers) was performed on an Agilent 6550 Q-TOF mass spectrometer using a binary gradient with a 1200 series HPLC system (Agilent) ${ }^{71}$.

The LC-MS/MS large peptide ( $>8 \mathrm{mer}$ ) analysis was performed according to the protocol outlined previously ${ }^{72}$. Methanol extracts $(90 \%(\mathrm{v} / \mathrm{v}))$ were dried under nitrogen. The samples were resuspended in $1 \%(\mathrm{v} / \mathrm{v})$ formic acid in $\mathrm{H}_{2} \mathrm{O}$ and solidphase extraction was performed using the Oasis TM columns. Recovered samples were lyophilised and resuspended in $50 \mathrm{mM}$ triethylammonium bicarbonate (TEAB) to a concentration of $0.33 \mu \mathrm{g} / \mu \mathrm{L}$, with $25 \mu \mathrm{g}$ of peptide material per sample used for downstream dimethyl labelling. Dimethyl labelling was performed ${ }^{72}$. A fresh $4 \%(\mathrm{v} / \mathrm{v})$ solution of light $\left(\mathrm{CH}_{2} \mathrm{O}\right)$ and medium $\left(\mathrm{CD}_{2} \mathrm{O}\right)$ formaldehyde was prepared and the light formaldehyde was added to the $\mathrm{C}_{2} \mathrm{GC} 3$ samples and the heavy formaldehyde was added to the corresponding $\mathrm{C}_{4}{ }^{\mathrm{Dd} 2}$ and $\mathrm{C}^{7 \mathrm{G} 8}$ samples. $0.6 \mathrm{M} \mathrm{NaBH}_{3} \mathrm{CN}$ was added, incubated for $1 \mathrm{~h}$ (ambient) and then quenched with $1 \%(\mathrm{v} / \mathrm{v})$ ammonia solution. Samples were re-acidified ( $100 \%$ formic acid) and $\mathrm{C} 2{ }^{\mathrm{GC} 03}$ samples were mixed equally (but separately) to both the $\mathrm{C} 4{ }^{\mathrm{Dd} 2}$ and $\mathrm{C} 66^{7 \mathrm{G} 8}$ samples. The three biological replicates were also reverse labelled (dimethyl heavy for $\mathrm{C} 22^{\mathrm{GC}} 33$ and dimethyl light for $\mathrm{C} 4{ }^{\mathrm{Dd} 2}$ and $\mathrm{C} 6^{7 \mathrm{G} 8}$ ) and analysed to ensure accurate quantitation between each cell line.

LC-MS/MS was carried out on a LTQ Orbitrap Elite (Thermo Scientific) with a nanoESI interface in conjunction with an Ultimate 3000 RSLC nanoHPLC (Dionex Ultimate 3000). The LC system was equipped with an Acclaim Pepmap nano-trap column (Dionex-C18, $100 \AA, 75 \mu \mathrm{m} \times 2 \mathrm{~cm}$ ) and an Acclaim Pepmap RSLC analytical column (Dionex-C18, $100 \AA, 75 \mu \mathrm{m} \times 50 \mathrm{~cm}$ ). The peptides were injected onto the enrichment column at an isocratic flow of $5 \mu \mathrm{L} / \mathrm{min}$ of $3 \%(\mathrm{v} / \mathrm{v})$ acetonitrile containing $0.1 \%(\mathrm{v} / \mathrm{v})$ formic acid before the enrichment column was switched in-line with the analytical column. The eluents were $0.1 \%(\mathrm{v} / \mathrm{v})$ formic acid (solvent A) and $100 \%(\mathrm{v} / \mathrm{v})$ acetonitrile in $0.1 \%(\mathrm{v} / \mathrm{v})$ formic acid (solvent $\mathrm{B}$ ). The flow gradient was (1) 0-6 min at 3\% (v/v) solvent B, (2) 6-95 min at 3-20\% (v/ v) solvent B, (3) $95-105 \mathrm{~min}$ at $20-40 \%(\mathrm{v} / \mathrm{v})$ solvent $\mathrm{B}$, (4) $105-110 \mathrm{~min}$ at $40-80 \%$ $(\mathrm{v} / \mathrm{v})$ solvent $\mathrm{B},(5) 110-115 \mathrm{~min}$ at $80-85 \%(\mathrm{v} / \mathrm{v})$ solvent $\mathrm{B},(6) 115-117 \mathrm{~min}$ at $85-3 \%(\mathrm{v} / \mathrm{v})$ and $(7)$ equilibrated at $3 \%(\mathrm{v} / \mathrm{v})$ solvent B for $10 \mathrm{~min}$ before the next sample injection. The LTQ Orbitrap Elite spectrometer was operated in the datadependent mode with nanoESI spray voltage of $1.8 \mathrm{kV}$, capillary temperature of $250{ }^{\circ} \mathrm{C}$ and S-lens RF value of $55 \%$. All spectra were acquired in positive mode with full scan MS spectra from $m / z 300-1650$ in the FT mode at 240,000 resolution. The automated gain control was set to a target value of $1.0 \mathrm{e}^{6}$ and a lock mass of 445.120025 was used. The top 20 most intense precursors were subjected to rapid collision induced dissociation (rCID) with normalised collision energy of 30 and activation $q$ of 0.25 . Dynamic exclusion of $30 \mathrm{~s}$ was applied for repeated precursors.

The small peptide data collected by LC-MS were converted into mzXML format using MSconvert and analysed using $\mathrm{MAVEN}^{73}$. The data were aligned using a polynomial degree of 5 and ion chromatograms were extracted using a permissive threshold (signal/noise $>4$ ) with a mass tolerance of $10 \mathrm{ppm}$. Peptide identification was achieved with a pre-existing exact mass peptide library and where possible, confirmation with MS-MS spectra matching and/or reference to authentic peptide standards. The data are presented as the mean across 2-6 biological replicates presented as $\log _{2}$ ratios.

The large peptide data were analysed using the MaxQuant (1.5.2.8) software package using the default parameters unless specified. Peptide identification was achieved using a custom protein library containing the top 50 proteins detected within the sample (the most abundantly degraded proteins in the P. falciparuminfected erythrocyte), using the unspecific digestion search mode and minimum peptide size of five amino acid residues. Variable modifications included oxidation and N-terminal acetylation, and no fixed modifications were permitted. Peptide spectral matching false-discovery rate was set to $1 \%$ using the reverse decoy database. Peptide quantification was achieved using the dimethyl lysine and dimethyl terminal light and medium labels ( 0 and 4 , respectively) and requantification performed when only singletons were detected. The raw heavy/light ratios (reflecting the relative peptide abundance between two cell lines) were compared to the inverse ratios acquired from the label switch data and the average taken between both samples. The mean of the $\log _{2}$ ratios across three biological replicates was calculated and peptides only detected in one replicate were removed from the dataset. The large peptide dataset was then merged with the small peptide dataset and where the same peptide was detected in both datasets the LC-MS/MS quantification was used. The data are presented as the mean across three biological replicates presented as $\log _{2}$ ratios.

Statistical analysis of the peptidomic data presented in Fig. 7 and Supplementary Data 3-5 was performed using the R package mclust $^{74}$. mclust fits a mixture model to the data using an expectation-maximisation algorithm and Bayes Information Criteria to select the optimal number of clusters and to estimate the mean and covariance structure for each cluster.

Quantification and statistical analyses. The statistical tests and data analyses were performed using InStat Version 3, Image J Version 1.8.0, SigmaPlot Windows Version 11.0, MAVEN Version 3.6, MaxQuant Version 1.5.2.8 or R statistical software Version 3.6.3. Statistical comparisons were made using oneway ANOVAs in conjunction with either Tukey's multiple comparisons test or a two-tailed one-sample $t$-test corrected for multiple hypothesis testing using the Benjamini-Hochberg procedure. Unless stated otherwise, all errors cited in the text and shown in the figures represent the standard error of the mean (SEM). Where not shown, error bars fall within the symbols. Significance was defined as $P<0.05$. The key statistical details for each dataset are included in the figure legends.

Reporting summary. Further information on research design is available in the Nature Research Reporting Summary linked to this article.

\section{Data availability}

The data supporting the findings of this study are available within the paper and Supplementary Information. Source data are provided with this paper.

Received: 7 October 2019; Accepted: 15 July 2020; Published online: 06 August 2020

\section{References}

1. Hayward, R., Saliba, K. J. \& Kirk, K. The $\mathrm{pH}$ of the digestive vacuole of Plasmodium falciparum is not associated with chloroquine resistance. J. Cell Sci. 119, 1016-1025 (2006).

2. Klonis, N. et al. Evaluation of $\mathrm{pH}$ during cytostomal endocytosis and vacuolar catabolism of haemoglobin in Plasmodium falciparum. Biochem J. 407, 343-354 (2007).

3. Orjih, A. U., Ryerse, J. S. \& Fitch, C. D. Hemoglobin catabolism and the killing of intraerythrocytic Plasmodium falciparum by chloroquine. Experientia 50, 34-39 (1994)

4. Becker, K. et al. Oxidative stress in malaria parasite-infected erythrocytes: host-parasite interactions. Int. J. Parasitol. 34, 163-189 (2004).

5. Rosenthal, P. J. Falcipains and other cysteine proteases of malaria parasites. Adv. Exp. Med. Biol. 712, 30-48 (2011).

6. Allen, R. J. \& Kirk, K. Cell volume control in the Plasmodium-infected erythrocyte. Trends Parasitol. 20, 7-10 (2004).

7. Krugliak, M., Zhang, J. \& Ginsburg, H. Intraerythrocytic Plasmodium falciparum utilizes only a fraction of the amino acids derived from the digestion of host cell cytosol for the biosynthesis of its proteins. Mol. Biochem. Parasitol. 119, 249-256 (2002).

8. Lew, V. L., Tiffert, T. \& Ginsburg, H. Excess hemoglobin digestion and the osmotic stability of Plasmodium falciparum-infected red blood cells. Blood 101, 4189-4194 (2003).

9. Mauritz, J. M. et al. The homeostasis of Plasmodium falciparum-infected red blood cells. PLoS Comput. Biol. 5, e1000339 (2009).

10. Martin, R. E., Shafik, S. H. \& Richards, S. N. Mechanisms of resistance to the partner drugs of artemisinin in the malaria parasite. Curr. Opin. Pharmacol. 42, 71-80 (2018).

11. Fidock, D. A. et al. Mutations in the P. falciparum digestive vacuole transmembrane protein PfCRT and evidence for their role in chloroquine resistance. Mol. Cell. 6, 861-871 (2000).

12. Cooper, R. A. et al. Alternative mutations at position 76 of the vacuolar transmembrane protein PfCRT are associated with chloroquine resistance and 
unique stereospecific quinine and quinidine responses in Plasmodium falciparum. Mol. Pharmacol. 61, 35-42 (2002).

13. Pulcini, S. et al. Mutations in the Plasmodium falciparum chloroquine resistance transporter, PfCRT, enlarge the parasite's food vacuole and alter drug sensitivities. Sci. Rep. 5, 14552-14567 (2015).

14. Martin, R. E. The transportome of the malaria parasite. Biol. Rev. Camb. Philos. Soc. 95, 305-332 (2020).

15. Martin, R. E. et al. Chloroquine transport via the malaria parasite's chloroquine resistance transporter. Science 325, 1680-1682 (2009).

16. Summers, R. L. et al. Diverse mutational pathways converge on saturable chloroquine transport via the malaria parasite's chloroquine resistance transporter. Proc. Natl Acad. Sci. USA 111, E1759-E1767 (2014).

17. Waller, K. L. et al. Chloroquine resistance modulated in vitro by expression levels of the Plasmodium falciparum chloroquine resistance transporter. J. Biol. Chem. 278, 33593-33601 (2003).

18. Bushell, E. et al. Functional profiling of a Plasmodium genome reveals an abundance of essential genes. Cell 170, 260-272 (2017).

19. Zhang, M. et al. Uncovering the essential genes of the human malaria parasite Plasmodium falciparum by saturation mutagenesis. Science 360, eaap7847 (2018).

20. Hrycyna, C. A. et al. Quinine dimers are potent inhibitors of the Plasmodium falciparum chloroquine resistance transporter and are active against quinoline-resistant P. falciparum. ACS Chem. Biol. 9, 722-730 (2014).

21. Richards, S. N. et al. Molecular mechanisms for drug hypersensitivity induced by the malaria parasite's chloroquine resistance transporter. PLoS Pathog. 12, e1005725 (2016)

22. Garg, A. et al. Targeting protein translation, RNA splicing, and degradation by morpholino-based conjugates in Plasmodium falciparum. Proc. Natl Acad. Sci. USA 112, 11935-11940 (2015).

23. Kublin, J. G. et al. Reemergence of chloroquine-sensitive Plasmodium falciparum malaria after cessation of chloroquine use in Malawi. J. Infect. Dis. 187, 1870-1875 (2003)

24. Ord, R. et al. Seasonal carriage of pfcrt and pfmdr1 alleles in Gambian Plasmodium falciparum imply reduced fitness of chloroquine-resistant parasites. J. Infect. Dis. 196, 1613-1619 (2007).

25. Sa, J. M. \& Twu, O. Protecting the malaria drug arsenal: halting the rise and spread of amodiaquine resistance by monitoring the PfCRT SVMNT type. Malar. J. 9, 374-376 (2010).

26. Wang, X. et al. Decreased prevalence of the Plasmodium falciparum chloroquine resistance transporter 76T marker associated with cessation of chloroquine use against $P$. falciparum malaria in Hainan, People's Republic of China. Am. J. Trop. Med. Hyg. 72, 410-414 (2005).

27. Lewis, I. A. et al. Metabolic QTL analysis links chloroquine resistance in Plasmodium falciparum to impaired hemoglobin catabolism. PLoS Genet. 10, e1004085 (2014).

28. Zhang, H., Howard, E. M. \& Roepe, P. D. Analysis of the antimalarial drug resistance protein Pfcrt expressed in yeast. J. Biol. Chem. 277, 49767-49775 (2002).

29. Warhurst, D. C., Craig, J. C. \& Adagu, I. S. Lysosomes and drug resistance in malaria. Lancet 360, 1527-1529 (2002).

30. Wieczorek, H., Putzenlechner, M., Zeiske, W. \& Klein, U. A vacuolar-type proton pump energizes $\mathrm{K}+/ \mathrm{H}+$ antiport in an animal plasma membrane. $J$. Biol. Chem. 266, 15340-15347 (1991).

31. Nessler, S. et al. Evidence for activation of endogenous transporters in Xenopus laevis oocytes expressing the Plasmodium falciparum chloroquine resistance transporter, PfCRT. J. Biol. Chem. 279, 39438-39446 (2004).

32. Patzewitz, E. M. et al. Glutathione transport: a new role for PfCRT in chloroquine resistance. Antioxid. Redox Signal. 19, 683-695 (2013).

33. Juge, N. et al. Plasmodium falciparum chloroquine resistance transporter is a $\mathrm{H}+$-coupled polyspecific nutrient and drug exporter. Proc. Natl Acad. Sci. USA 112, 3356-3361 (2015).

34. Bakouh, N. et al. Iron is a substrate of the Plasmodium falciparum chloroquine resistance transporter PfCRT in Xenopus oocytes. J. Biol. Chem. 292, 16109-16121 (2017).

35. Martin, R. E. \& Kirk, K. The malaria parasite's chloroquine resistance transporter is a member of the drug/metabolite transporter superfamily. Mol. Biol. Evol. 21, 1938-1949 (2004).

36. Lehane, A. M., Hayward, R., Saliba, K. J. \& Kirk, K. A verapamil-sensitive chloroquine-associated $\mathrm{H}+$ leak from the digestive vacuole in chloroquineresistant malaria parasites. J. Cell Sci. 121, 1624-1632 (2008).

37. Lehane, A. M. \& Kirk, K. Chloroquine resistance-conferring mutations in pfcrt give rise to a chloroquine-associated $\mathrm{H}+$ leak from the malaria parasite's digestive vacuole. Antimicrob. Agents Chemother. 52, 4374-4380 (2008).

38. Martin, R. E. et al. Saquinavir inhibits the malaria parasite's chloroquine resistance transporter. Antimicrob. Agents Chemother. 56, 2283-2289 (2012).

39. Bellanca, S. et al. Multiple drugs compete for transport via the Plasmodium falciparum chloroquine resistance transporter at distinct but interdependent sites. J. Biol. Chem. 289, 36336-36351 (2014).
40. Deane, K. J., Summers, R. L., Lehane, A. M., Martin, R. E. \& Barrow, R. A. Chlorpheniramine analogues reverse chloroquine resistance in Plasmodium falciparum by inhibiting PfCRT. ACS Med. Chem. Lett. 5 , 576-581 (2014).

41. Van Schalkwyk, D. A. et al. Verapamil-sensitive transport of quinacrine and methylene blue via the Plasmodium falciparum chloroquine resistance transporter reduces the parasite's susceptibility to these tricyclic drugs. J. Infect. Dis. 213, 800-810 (2016).

42. Bozzi, A. T., Bane, L. B., Zimanyi, C. M. \& Gaudet, R. Unique structural features in an Nramp metal transporter impart substrate-specific proton cotransport and a kinetic bias to favor import. J. Gen. Physiol. 151, 1413-1429 (2019).

43. Deves, R., Chavez, P. \& Boyd, C. A. Identification of a new transport system $(\mathrm{y}+\mathrm{L})$ in human erythrocytes that recognizes lysine and leucine with high affinity. J. Physiol. 454, 491-501 (1992).

44. Torrents, D. et al. Identification and characterization of a membrane protein $(\mathrm{y}+\mathrm{L}$ amino acid transporter-1) that associates with $4 \mathrm{~F} 2 \mathrm{hc}$ to encode the amino acid transport activity $\mathrm{y}+\mathrm{L}$. A candidate gene for lysinuric protein intolerance. J. Biol. Chem. 273, 32437-32445 (1998).

45. Pelleau, S. et al. Adaptive evolution of malaria parasites in French Guiana: reversal of chloroquine resistance by acquisition of a mutation in pfcrt. Proc. Natl Acad. Sci. USA 112, 11672-11677 (2015).

46. Petersen, I. et al. Balancing drug resistance and growth rates via compensatory mutations in the Plasmodium falciparum chloroquine resistance transporter. Mol. Microbiol. 97, 381-395 (2015).

47. Sidhu, A. B., Verdier-Pinard, D. \& Fidock, D. A. Chloroquine resistance in Plasmodium falciparum malaria parasites conferred by pfcrt mutations. Science 298, 210-213 (2002).

48. Sonoiki, E. et al. Altered Plasmodium falciparum sensitivity to the antiretroviral protease inhibitor lopinavir associated with polymorphisms in pfmdr1. Antimicrob. Agents Chemother. 61, e01949-16 (2017).

49. Agarwal, S., Pal, D. \& Mitra, A. K. Both P-gp and MRP2 mediate transport of lopinavir, a protease inhibitor. Int J. Pharm. 339, 139-147 (2007).

50. Teng, R. et al. 1H-NMR metabolite profiles of different strains of Plasmodium falciparum. Biosci. Rep. 34, e00150 (2014).

51. Lee, A. H. et al. Evidence for regulation of hemoglobin metabolism and intracellular ionic flux by the Plasmodium falciparum chloroquine resistance transporter. Sci. Rep. 8, 13578-13590 (2018).

52. Tindall, S. M. et al. Heterologous expression of a novel drug transporter from the malaria parasite alters resistance to quinoline antimalarials. Sci. Rep. 8, 2464-2474 (2018).

53. Duru, V. et al. Plasmodium falciparum dihydroartemisinin-piperaquine failures in Cambodia are associated with mutant $\mathrm{K} 13$ parasites presenting high survival rates in novel piperaquine in vitro assays: retrospective and prospective investigations. BMC Med. 13, 305-315 (2015).

54. Agrawal, S. et al. Association of a novel mutation in the Plasmodium falciparum chloroquine resistance transporter with decreased piperaquine sensitivity. J. Infect. Dis. 216, 468-476 (2017).

55. $\mathrm{Mu}$, J. et al. Recombination hotspots and population structure in Plasmodium falciparum. PLoS Biol. 3, e335 (2005).

56. Lehane, A. M. \& Kirk, K. Efflux of a range of antimalarial drugs and 'chloroquine resistance reversers' from the digestive vacuole in malaria parasites with mutant PfCRT. Mol. Microbiol. 77, 1039-1051 (2010).

57. Allen, R. J. \& Kirk, K. Plasmodium falciparum culture: the benefits of shaking Mol. Biochem. Parasitol. 169, 63-65 (2010).

58. Drexler, H. G. \& Uphoff, C. C. Mycoplasma contamination of cell cultures: incidence, sources, effects, detection, elimination, prevention. Cytotechnology 39, 75-90 (2002).

59. Broer, S. et al. Comparison of lactate transport in astroglial cells and monocarboxylate transporter 1 (MCT 1) expressing Xenopus laevis oocytes. Expression of two different monocarboxylate transporters in astroglial cells and neurons. J. Biol. Chem. 272, 30096-30102 (1997).

60. Taylor, M. A. \& Smith, L. D. Accumulation of free amino acids in growing Xenopus laevis oocytes. Dev. Biol. 124, 287-290 (1987).

61. Goldberg, D. E. et al. Hemoglobin degradation in the human malaria pathogen Plasmodium falciparum: a catabolic pathway initiated by a specific aspartic protease. J. Exp. Med. 173, 961-969 (1991).

62. Gluzman, I. Y. et al. Order and specificity of the Plasmodium falciparum hemoglobin degradation pathway. J. Clin. Invest. 93, 1602-1608 (1994).

63. Francis, S. E. et al. Molecular characterization and inhibition of a Plasmodium falciparum aspartic hemoglobinase. EMBO J. 13, 306-317 (1994).

64. Subramanian, S. et al. Hemoglobin cleavage site-specificity of the Plasmodium falciparum cysteine proteases falcipain-2 and falcipain-3. PLoS ONE 4, e5156 (2009).

65. Eggleson, K. K., Duffin, K. L. \& Goldberg, D. E. Identification and characterization of falcilysin, a metallopeptidase involved in hemoglobin catabolism within the malaria parasite Plasmodium falciparum. J. Biol. Chem. 274, 32411-32417 (1999). 
66. Banerjee, R. et al. Four plasmepsins are active in the Plasmodium falciparum food vacuole, including a protease with an active-site histidine. Proc. Nat Acad. Sci. USA 99, 990-995 (2002).

67. Schneider, C. A., Rasband, W. S. \& Eliceiri, K. W. NIH Image to ImageJ: 25 years of image analysis. Nat. Methods 9, 671-675 (2012).

68. Smilkstein, M., Sriwilaijaroen, N., Kelly, J. X., Wilairat, P. \& Riscoe, M. Simple and inexpensive fluorescence-based technique for high-throughput antimalarial drug screening. Antimicrob. Agents Chemother. 48, 1803-1806 (2004).

69. Spry, C. et al. Pantothenamides are potent, on-target inhibitors of Plasmodium falciparum growth when serum pantetheinase is inactivated. PLOS ONE 8, e54974 (2013).

70. Cobbold, S. A. \& Mcconville, M. J. Determining the mode of action of antimalarial drugs using time-resolved LC-MS-based metabolite profiling. Methods Mol. Biol. 1859, 225-239 (2019).

71. Kennedy, K. et al. Delayed death in the malaria parasite Plasmodium falciparum is caused by disruption of prenylation-dependent intracellular trafficking. PLoS Biol. 17, e3000376 (2019).

72. Boersema, P. J., Raijmakers, R., Lemeer, S., Mohammed, S. \& Heck, A. J. Multiplex peptide stable isotope dimethyl labeling for quantitative proteomics. Nat. Protoc. 4, 484-494 (2009).

73. Clasquin, M. F., Melamud, E. \& Rabinowitz, J. D. LC-MS data processing with MAVEN: a metabolomic analysis and visualization engine. Curr. Protoc. Bioinformatics Chapter 14, Unit14.11 (2012).

74. Scrucca, L., Fop, M., Murphy, T. B. \& Raftery, A. E. mclust 5: clustering, classification and density estimation using gaussian finite mixture models. R. J. 8, 289-317 (2016).

75. Carter, N. S. et al. Isolation and functional characterization of the PfNT1 nucleoside transporter gene from Plasmodium falciparum. J. Biol. Chem. 275, 10683-10691 (2000).

76. Parker, M. D. et al. Identification of a nucleoside/nucleobase transporter from Plasmodium falciparum, a novel target for anti-malarial chemotherapy. Biochem J. 349, 67-75 (2000).

\section{Acknowledgements}

We thank Prof David Fidock for providing the transfectant $P$. falciparum lines, Prof Jean Chmielewski for providing $\mathrm{Q}_{2} \mathrm{C}$, Prof Kiaran Kirk for providing several of the radiolabelled solutes, Dr Teresa Neeman for assistance with statistical modelling, Dr Adele Lehane for helpful discussions and comments on the manuscript, Megan Nash for conducting preliminary cis-inhibition oocyte assays, and the Canberra Branch of the Australian Red Cross Blood Service for the provision of blood. This work was supported by the Australian Research Council (fellowship 1053082 to R.E.M.), the L'Oréal Australia For Women in Science program (to R.E.M.), the National Health and Medical Research Council (Project Grants 1007035 and 1127338 to R.E.M., fellowship 1154540 to M.J.M., fellowship 1053082 to R.E.M. and fellowship 1120690 to R.L.S.), the National Institutes of
Health (1DP2OD001315-01 to M.L.) and the Australian Department of Education (Australian Postgraduate Awards to S.H.S., S.N.R. and R.L.S.).

\section{Author contributions}

Conceptualisation: S.H.S. and R.E.M.; methodology: S.H.S., S.A.C., M.J.M. and R.E.M.; formal analysis: S.H.S., S.A.C. and R.E.M.; investigation: S.H.S., S.A.C., K.B., S.N.R., N.S.L., R.L.S. and R.E.M.; resources: S.H.S., K.B., S.N.R., N.S.L., M.L. and S.J.H.; writing-original draft: S.H.S., S.A.C. and R.E.M.; writing-review and editing: S.H.S., S.A.C., S.N.R., R.L.S., M.J.M. and R.E.M.; visualisation: S.H.S., S.A.C., R.L.S. and R.E.M.; Supervision: M.J.M. and R.E.M.; project administration: R.E.M.; funding acquisition: R.E.M.

\section{Competing interests}

The authors declare no competing interests.

\section{Additional information}

Supplementary information is available for this paper at https://doi.org/10.1038/s41467020-17781-6.

Correspondence and requests for materials should be addressed to R.E.M.

Peer review information Nature Communications thanks Thomas Wellems and the other, anonymous, reviewer(s) for their contribution to the peer review of this work. Peer reviewer reports are available.

Reprints and permission information is available at http://www.nature.com/reprints

Publisher's note Springer Nature remains neutral with regard to jurisdictional claims in published maps and institutional affiliations.

\begin{abstract}
(c) (i) Open Access This article is licensed under a Creative Commons Attribution 4.0 International License, which permits use, sharing, adaptation, distribution and reproduction in any medium or format, as long as you give appropriate credit to the original author(s) and the source, provide a link to the Creative Commons license, and indicate if changes were made. The images or other third party material in this article are included in the article's Creative Commons license, unless indicated otherwise in a credit line to the material. If material is not included in the article's Creative Commons license and your intended use is not permitted by statutory regulation or exceeds the permitted use, you will need to obtain permission directly from the copyright holder. To view a copy of this license, visit http://creativecommons.org/ licenses/by/4.0/.
\end{abstract}

(c) The Author(s) 2020 